\title{
Dopaminergic Modulation of Spinal Neuronal Excitability
}

\author{
Pengcheng Han, Stan T. Nakanishi, Michelle A. Tran, and Patrick J. Whelan \\ Hotchkiss Brain Institute, University of Calgary, Calgary, Alberta, Canada T2N 4N1
}

It is well recognized that dopamine (DA) can modulate spinal networks and reflexes. DA fibers and receptors are present in the spinal cord, and evidence for DA release within the spinal cord has been published. A critical gap is the lack of data regarding dopaminergic modulation of intrinsic and synaptic properties of motoneurons and ventral interneurons in the mammalian spinal cord. In this paper, we address this issue by examining the cellular mechanisms underlying the excitatory effect of DA on motor systems. We examine the effects of DA on two classes of cells important for motor control, motoneurons and Hb9 interneurons, located in lamina VIII. We show that DA can boost excitability in spinal motoneurons by decreasing the first spike latency and the afterhyperpolarization. Collectively, this leads to an increase in the frequency-current slope likely attributable to modulation of $I_{\mathrm{A}}$ and $\mathrm{SK}_{\mathrm{Ca}}$ (small-conductance calciumactivated $\mathrm{K}^{+}$channel) currents. We also demonstrate that DA increases glutamatergic transmission onto motoneurons. Our data also suggest that DA stabilizes the rhythmic output of conditionally bursting interneurons. Collectively, these data indicate that DA has widespread actions on intrinsic and synaptic properties of ventral spinal neurons.

Key words: monoamines; spinal cord; central pattern generators; motoneurons; neuromodulators; mouse

\section{Introduction}

The role of most monoamines in the descending control of mammalian spinal circuits has been extensively investigated at the cellular level (Rekling et al., 2000; Schmidt and Jordan, 2000; Hochman et al., 2001; Jankowska, 2001). Dopamine (DA) is the notable exception in that the majority of the work has been performed using nonterrestrial species, such as the lamprey (McPherson and Kemnitz 1994; Kemnitz et al., 1995; Schotland et al., 1995; Kemnitz, 1997; Pierre et al., 1997; Svensson et al., 2003). Several lines of evidence suggest that DA modulates mammalian spinal reflex and locomotor circuits (Skoog and Noga, 1995; Kiehn and Kjaerulff, 1996; Whelan et al., 2000; Barriere et al., 2004; Clemens and Hochman, 2004; Madriaga et al., 2004; Christie and Whelan, 2005; Clemens et al., 2005; Gordon and Whelan, 2006), and clinically it has been suggested that "restless leg syndrome" is caused by a reduction in spinal release of dopamine (Clemens et al., 2006). In the neonatal rat and mouse, bath application of DA in vitro effectively elicits and modulates fictive locomotor patterns (Smith et al., 1988; Kiehn and Kjaerulff, 1996; Barriere et al., 2004; Madriaga et al., 2004). This dopaminergic excitation of mammalian spinal locomotor circuits appears to be facilitated mainly by $\mathrm{D}_{1}$ receptors (Maitra et al., 1993; Seth et al., 1993; Barriere et al., 2004; Madriaga et al., 2004), in contrast to the lamprey in which DA promotes excitability through a $\mathrm{D}_{2}$ receptor-based pathway (Schotland et al., 1995).

Received Nov. 23, 2006; revised 0ct. 15, 2007; accepted 0ct. 17, 2007

This work was supported by the Canadian Institutes of Health Research, the Heart and Stroke Foundation of Canada, the Christopher Reeve Paralysis Foundation, and the Alberta Heritage Foundation for Medical Research. P.H. and S.T.N. received fellowships from the Hotchkiss Brain Institute. We thank Mike Molineux and Hamish Mehaffey for contributing part of the Matlab code used for our spike analysis.

Correspondence should be addressed to Patrick J. Whelan, Department of Physiology and Biophysics, HSC 2119, University of Calgary, Calgary, Alberta, Canada T2N 4N1. E-mail: whelan@ucalgary.ca.

DOI:10.1523/JNEUROSCI.1279-07.2007

Copyright $\odot 2007$ Society for Neuroscience ～0270-6474/07/2713192-13\$15.00/0
DA receptors and fibers projecting from the diencephalon (A11 area) are present in the ventral horn of the adult spinal cord (Bjorklund and Skagerberg, 1979; Weil-Fugazza and Godefroy, 1993; Yoshida and Tanaka, 1988; Holstege et al., 1996; Qu et al., 2006), an area in which motor circuits are located, and mice with lesions of the A11 area show deficits in motor control (Clemens et al., 2006). Microdialysis measurements in the first week of life show release of DA and its metabolites in the ventral horn of neonatal rats during fictive locomotion (Gerin et al., 1995; Jordan and Schmidt, 2002).

Collectively, these studies point to an important role for DA in modulating sensorimotor function in the developing and adult spinal cord. However, intracellular recordings examining DA modulation of spinal motoneurons and ventral interneurons have not been published. Accordingly, there is a gap in our knowledge regarding the modulation of intrinsic neuronal properties and synaptic transmission by DA.

In this paper, we examine cellular mechanisms underlying the modulatory effect of DA on spinal motor circuits. We investigate the effects of DA on two classes of cells important for motor control, motoneurons and $\mathrm{Hb} 9$ interneurons, located in lamina VIII (Hinckley et al., 2005b; Wilson et al., 2005; Hinckley and Ziskind-Conhaim, 2006). Our data suggest that DA can boost excitability in spinal motor systems by decreasing $I_{\mathrm{A}}$ and $\mathrm{SK}_{\mathrm{Ca}}$ (small-conductance calcium-activated $\mathrm{K}^{+}$channel) currents and increasing glutamatergic synaptic transmission. Furthermore, our data suggest that DA stabilizes rhythmic activity in Hb9 cells.

\section{Materials and Methods}

Experiments were performed on Swiss Webster mice (Charles River Laboratories, Wilmington, MA) 4- to 8-d-old [postnatal day 4 (P4) to P8; weight 3.4-6.3 g; $n=73$ ] and Hb9:green fluorescent protein (GFP) mice (The Jackson Laboratory, Bar Harbor, MA) aged P1-P7 (weight 1.7-4.8 $\mathrm{g} ; n=49)$. The animals were anesthetized by hypothermia (P2-P4) or by 
halothane (older than P4) using procedures approved by the University of Calgary Animal Care Committee.

\section{Tissue preparation}

Isolated spinal cord preparations. Animals (P4-P5) were rapidly decapitated and eviscerated, and the remaining tissue was placed in a dissection chamber filled with oxygenated $\left(95 \% \mathrm{O}_{2}, 5 \% \mathrm{CO}_{2}\right)$ artificial CSF (ACSF) (in mM: $128 \mathrm{NaCl}, 4 \mathrm{KCl}, 1.5 \mathrm{CaCl}_{2}, 1 \mathrm{MgSO}_{4}, 0.5 \mathrm{Na}_{2} \mathrm{HPO}_{4}, 21$ $\mathrm{NaHCO}_{3}$, and $30 \mathrm{D}$-glucose). A ventral laminectomy exposed the cord, and the ventral and dorsal roots were cut. The spinal cord was transversely transected at $\mathrm{T} 1-\mathrm{T} 3$ and was gently removed from the vertebral column to the level of the cauda equina. The ACSF containing the isolated spinal cord was allowed to warm up to room temperature $(\sim 24-$ $\left.25^{\circ} \mathrm{C}\right)$ in the dissection chamber $(\sim 30 \mathrm{~min})$. Then, the preparation was transferred to the recording chamber and superfused with oxygenated ACSF (concentrations similar to dissecting solution). The bath solution was then heated gradually from room temperature to $27^{\circ} \mathrm{C}$ (Whelan et al., 2000).

Slice preparations. Under sterile conditions, 3-4 $\mu \mathrm{l}$ of 2.5\% FluoroGold (FG) (Fluorochrome, Denver, CO) in sterile saline was injected into the triceps surae (TS) muscle of the right hindlimb of 73 neonatal mice (P2-P4). To ensure the selectivity of this approach, we injected FG into the tibialis anterior (TA) muscle group of five mice as a control. TA motoneurons were labeled in more rostral segments (L2-L3) compared with TS motoneurons. One to $5 \mathrm{~d}$ later, the spinal cord was dissected free as described except in ice-cold, oxygenated sucrose-ACSF solution (in mм: $25 \mathrm{NaCl}, 188$ sucrose, $1.9 \mathrm{KCl}, 10 \mathrm{MgSO}_{4}, 1.2 \mathrm{Na}_{2} \mathrm{HPO}_{4}, 26$ $\mathrm{NaHCO}_{3}$, and 25 D-glucose) was used (Miles et al., 2005). The isolated spinal cord was immediately transferred to a precooled $\left(4^{\circ} \mathrm{C}\right)$ slicing chamber and stabilized in an upright position onto an agar block using $20 \%$ gelatin. The slicing chamber was then filled with ice-cold, oxygenated sucrose-ACSF solution that was kept chilled and continuously oxygenated. Transverse sections $(350 \mu \mathrm{m})$ were cut (Vibrotome VT1000S; Leica, Bussloch, Germany), and the slices were collected in a chamber containing prewarmed $\left(36^{\circ} \mathrm{C}\right)$, oxygenated recovery ACSF (in mM: 119 $\mathrm{NaCl}, 1.9 \mathrm{KCl}, 1 \mathrm{CaCl}_{2}, 10 \mathrm{MgSO}_{4}, 1.2 \mathrm{Na}_{2} \mathrm{HPO}_{4}, 26 \mathrm{NaHCO}_{3}, 10$ D-glucose, 1.5 kyurenic acid, 2 lactic acid, and 3\% dextran) and equilibrated for at least $45 \mathrm{~min}$ before being transferred to a holding ACSF (the same solution as recovery ACSF except without kyurenic acid, lactic acid, and dextran) until being moved onto the recording rig. All the blockers and stimulants were dissolved and applied with the recording ACSF solution [in mm: $119 \mathrm{NaCl}, 1.9 \mathrm{KCl}, 1 \mathrm{CaCl}_{2}, 10 \mathrm{MgSO}_{4}, 1.2 \mathrm{Na}_{2} \mathrm{HPO}_{4}, 26$ $\mathrm{NaHCO}_{3}$, and 10 D-glucose $\left.\left(24-25^{\circ} \mathrm{C}\right)\right]$.

\section{Pharmacology}

The synaptic blockers used in these experiments include the following: CNQX (AMPA/kainate receptor antagonist, $20 \mu \mathrm{M}$; Sigma-Aldrich, St. Louis, MO), AP-5 (NMDA receptor antagonist, $100 \mu \mathrm{M}$; Sigma-Aldrich), strychnine hydrochloride (glycine receptor antagonist, $10 \mu \mathrm{M}$; SigmaAldrich), and picrotoxin $\left(\mathrm{GABA}_{\mathrm{A}}\right.$ receptor, chloride channel blocker, 50 $\mu \mathrm{M}$; Sigma-Aldrich). Channel blockers used were 4-aminopyridine (4AP) $\left(\mathrm{K}^{+}\right.$-channel blocker, $200 \mu \mathrm{M}$; Tocris Bioscience, Ellisville, $\left.\mathrm{MO}\right)$, apamin $\left(\mathrm{Ca}^{2+}\right.$-activated $\mathrm{K}^{+}$-channel blocker, $100 \mathrm{~nm}$; Tocris Bioscience), and tetrodotoxin citrate (TTX) $\left(\mathrm{Na}^{+}\right.$channel blocker, $1 \mu \mathrm{M}$; Tocris Bioscience). Other pharmacological reagents used include the following: NMDA (20 $\mu \mathrm{M}$; Sigma-Aldrich), serotonin hydrochloride (5HT) $(20 \mu \mathrm{M}$; Sigma-Aldrich), and dopamine hydrochloride (50 or 100 $\mu \mathrm{M}$; Sigma-Aldrich). Washout time of drugs varied from 5 to $20 \mathrm{~min}$, and recording recommenced when the membrane potential had stabilized.

\section{Electrophysiology}

Isolated spinal cord preparations. We used the isolated spinal cord preparation to examine the effects of DA on populations of interneurons and motoneurons in which fast glutamatergic and inhibitory inputs were blocked. We recorded electrotonically propagated potentials from ipsilateral S1, L5, and L2 ventral roots (O'Donovan, 1987; Whelan et al., 2000). Similar potentials were recorded from interneurons that projected into the ventrolateral funiculus (VLF). A cut was made in the VLF with microclippers, and a piece of VLF approximately half a segment in length was exposed for recording by a suction electrode (Fedirchuk et al., 1999).
We elicited a reflex response in the L5 ventral root neurogram by stimulating the ipsilateral L5 dorsal root $(0.6 \mathrm{~ms}$ pulse, $>40$ s between pulses, five pulses) and determined the threshold (T). Next, we stimulated the L5 dorsal root at $2 \mathrm{~T}$ before and after the application of the synaptic blockers to test for the effectiveness of the synaptic blockade. Data were bandpass filtered $(0.1-1 \mathrm{kHz}$ ), sampled at $5 \mathrm{kHz}$, and digitized (Digidata 1322A; Molecular Devices, Union City, CA). The peak response within a 6-16 $\mathrm{ms}$ window following the stimulus pulse was calculated and subtracted from the mean baseline (10 ms window before stimulus pulse). The percentage reduction after the addition of the blockers was calculated from the two peak response values. Then, DA was bath applied, and the slow electrotonically propagated responses were recorded from all neurograms. Electrophysiological recordings were amplified (1000-20,000 times), low-pass [direct current (DC), 0.03-1 kHz] or bandpass (0.03-1 $\mathrm{kHz}$ ) filtered and digitized at $2-5 \mathrm{kHz}$ for future analysis. Data were analyzed and digitally filtered using Clampfit 8.0. Student's $t$ tests were performed to determine whether the changes were significant $(p<$ $0.05)$.

Slice preparations. The lumbar spinal cord slice was placed into the recording chamber and superfused with oxygenated ACSF solution (in mм: $128 \mathrm{NaCl}, 4 \mathrm{KCl}, 1.5 \mathrm{CaCl}_{2}, 1 \mathrm{MgSO}_{4}, 0.5 \mathrm{Na}_{2} \mathrm{HPO}_{4}, 21 \mathrm{NaHCO}_{3}$, and $30 \mathrm{D}$-glucose) at an approximate rate of $\sim 2 \mathrm{ml} / \mathrm{min}$. Electrodes were pulled from borosilicate glass on a P87 Flaming/Brown puller (Sutter Instruments, Novato, CA) and had resistances in the range of 3-5 M $\Omega$. The internal pipette solution contained (in $\mathrm{mm}$ ) $130 \mathrm{~K}$-gluconate, 7 $\mathrm{NaCl}, 0.1$ EGTA, 10 HEPES, $0.3 \mathrm{MgCl}_{2}$, $2 \mathrm{ATP}$, and $0.5 \mathrm{GTP}$, adjusted to $\mathrm{pH} 7.3$ with $\mathrm{KOH}$, or in select experiments, $150 \mathrm{CsCl}, 1$ EGTA, 10 HEPES, $0.1 \mathrm{CaCl}_{2}, 4.6 \mathrm{MgCl}_{2}$, $2 \mathrm{ATP}$, and $0.5 \mathrm{GTP}$. The liquid junction potential between internal and external solutions was calculated using pClamp software to be $11.7 \mathrm{mV}$ in K-gluconate internal solution and 8.6 $\mathrm{mV}$ in Cs-based internal solution and corrected. FG-positive $\left(\mathrm{FG}^{+}\right)$or $\mathrm{GFP}^{+}$cells were located under fluorescence (BX51; Olympus Optical, Center Valley, PA) and marked for future identification. Neurons were visualized for whole-cell patch using differential interference contrast optics and infrared light transmission. In certain experiments, glutamatergic and/or inhibitory fast neurotransmission were blocked. The data were low-pass filtered $(10 \mathrm{kHz})$ and digitized (sampling rate of $20 \mathrm{kHz}$ ) for off-line analyses (Digidata 1322A, Clampex 8 and 10; Molecular Devices). The channel blockers ( $2 \mathrm{~mm} 4-\mathrm{AP}$ and $100 \mathrm{~nm}$ apamin) and pharmacological reagents ( $20 \mu \mathrm{M}$ NMDA, $20 \mu \mathrm{M} 5-\mathrm{HT}$, and $50 \mu \mathrm{M} \mathrm{DA}$ ) were dissolved in ACSF and prepared fresh before each experiment. DA concentrations were based on previous studies using this concentration range to modulate spinal networks in mouse (Jiang et al., 1999a; Whelan et al., 2000; Christie and Whelan, 2005; Hinckley et al., 2005a). Currentclamp analyses were performed using Clampfit, and step current protocols were analyzed using custom-designed programs (Matlab; MathWorks, Natick, MA). Spikes were detected by differentiating the voltage traces and setting spike threshold as a multiple of the SD of baseline noise. Various properties were automatically measured including interspike interval (ISI). The average spike frequency (in hertz) was calculated by taking the mean ISI across a current step and was used to construct frequency-current $(f-I)$ plots. Spike regularity was calculated by using a coefficient of variance $(\mathrm{CV})$ measure, calculated by taking the ratio of the SD of the ISI divided by the mean ISI for each cell and then multiplying by 100 to express this dimensionless value as a percentage. A step current protocol was used to determine the rheobase, which was defined as the injected current necessary to elicit the first action potential. The data are presented as mean \pm SEM, with $n=$ the number of cells unless indicated otherwise. Wherever necessary, a percentage change was given by normalizing corresponding control value to $100 \%$ in each individual cell. Differences were compared using paired Student's $t$ tests or a repeatedmeasures one-way ANOVA. A post hoc pairwise Tukey's test was performed if significant differences were found $(p<0.05)$ (SigmaStat; SPSS, Chicago, IL). Voltage-clamp analyses were performed using Clampfit. Cumulative probability plots for spontaneous or miniature EPSCs (sEPSCs or mEPSCs, respectively) amplitude and frequency were generated using commercial software [Minianalysis (Synaptosoft, Decatur, GA) and Origin 5.0 (Microcal, Northampton, MA)]. In some experiments, we puffed on AMPA (puff pipette contained $100 \mu \mathrm{M}$ AMPA plus 
$1 \mu \mathrm{M}$ TTX dissolved in ACSF, and the bath solution contained $1 \mu \mathrm{M}$ TTX dissolved in ACSF) to test whether DA modulated EPSCs. The puff electrode was advanced to an area just above the target cell. The target cell was then whole-cell patched as described previously, and responses were tested in the presence of TTX $(1 \mu \mathrm{M})$. A triggering protocol was set up in Clampex to trigger the Picospritzer and record the resultant EPSC (duration of puff, $500 \mathrm{~ms}$; one puff every minute for duration of the protocol; data sweep recorded for $20 \mathrm{~s}$ ). Three control puffs were applied. DA was then bath applied for a duration of 5 min before washing out. The peak amplitude was calculated and a first-order exponential function was applied to the decay phase of the EPSC to determine the time constant (Sharifullina et al., 2004).

\section{Results}

Dopamine increases the excitability of isolated populations of motoneurons

The first question we addressed was whether DA could increase the excitability of populations of motoneurons and ventral interneurons in which fast glutamatergic and inhibitory transmission was blocked. To address this question, we used isolated spinal cord preparations in which we could record from multiple populations of cells during each experiment. We first stimulated the L5 dorsal root at 2T before and after application of the antagonists to test the effectiveness of our blockade of fast synaptic transmission. The peak potential of the reflex response recorded from the L5 ventral root neurogram decreased to $10.53 \pm 3.76 \%$ of control values after administration of the blockers $(n=6)$ (Fig. 1A).

During bath application of DA, increases in electrotonic slow DC potentials were observed in all neurograms (VLF, L2, L5, and S1). These increases reflect an average of membrane events across neurons that project axons into the recorded ventral roots or VLF tissue. The time course of the slow DC potential has been established previously to correspond closely to the membrane potential trajectory recorded intracellularly (O'Donovan, 1987). Therefore, DA excites populations of motoneurons and VLF projecting interneurons (Fig. $1 B, C$ ).

\section{DA increases excitability of individual motoneurons}

Our data suggested that DA affected intrinsic properties of a large population of motoneurons and interneurons. To examine the cellular mechanisms underlying such an increase in excitability, we turned to whole-cell patch approaches using spinal cord slice preparations. We focused on an identified subpopulation of motoneurons, namely those innervating the TS labeled by intramuscular injection of Fluoro-Gold.

In preliminary experiments, we tested the effects of DA on motoneuronal excitability in the absence of synaptic blockers in nine cells. Six of nine cells showed spontaneous firing if no hyperpolarizing current was injected. Figure $2 \mathrm{~A}$ shows an example of a motoneuron firing spontaneously at resting membrane potential. DA increased the average spike frequency from $11.4 \pm 4.6$ $\mathrm{Hz}$ (control) to $16.1 \pm 4.8 \mathrm{~Hz}$ ( $60 \%$ increment when control was normalized to one for each individual cell), which recovered to $10.9 \pm 3.5 \mathrm{~Hz}$ after washout $(n=6 ; p<0.05)$ (Fig. $2 D)$. These data suggest that DA increases the spontaneous spike frequency. Although the firing pattern appeared more regular in DA compared with control conditions, an analysis of CV of the ISI did not show a significant difference (ISI CV in control, $20.5 \pm 8.6$; ISI CV in DA, $18.4 \pm 6.9$; ISI CV in wash, 17.2 \pm 9.3$)$. The remaining three cells did not show spontaneous firing (Fig. $2 E, F$ ). Nevertheless, DA depolarized the cells beyond spike threshold. One can see the intense period of firing in the cell in $\boldsymbol{E}$, and this initial period of intense activity matches our population recording ob-
A

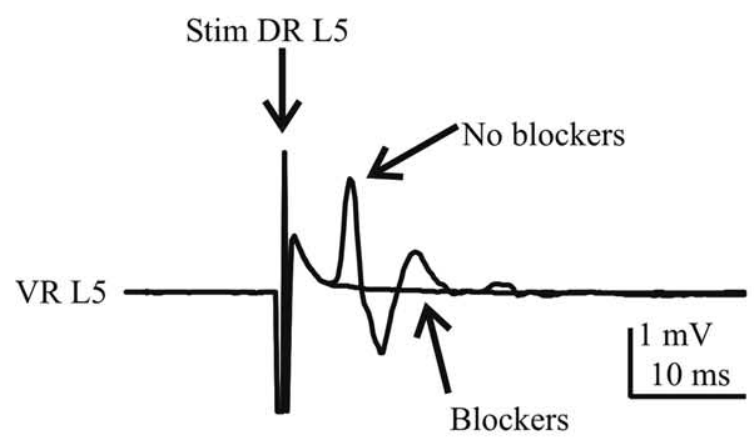

B

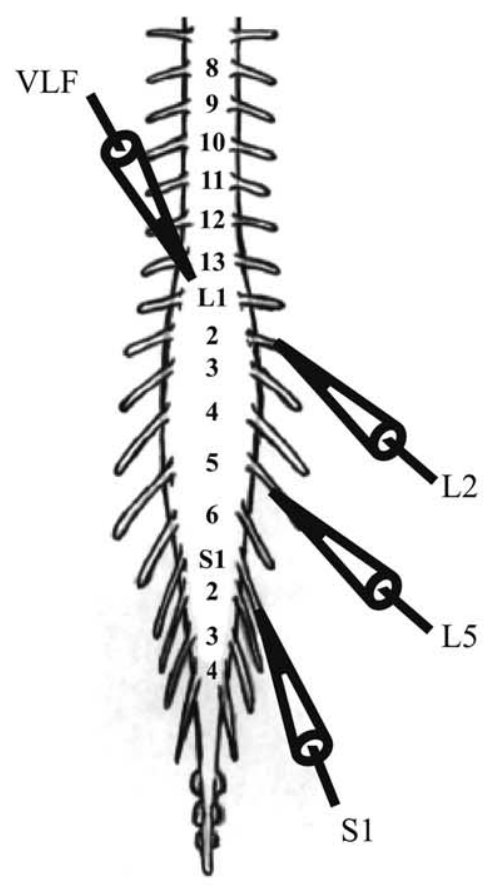

$\mathrm{C}$

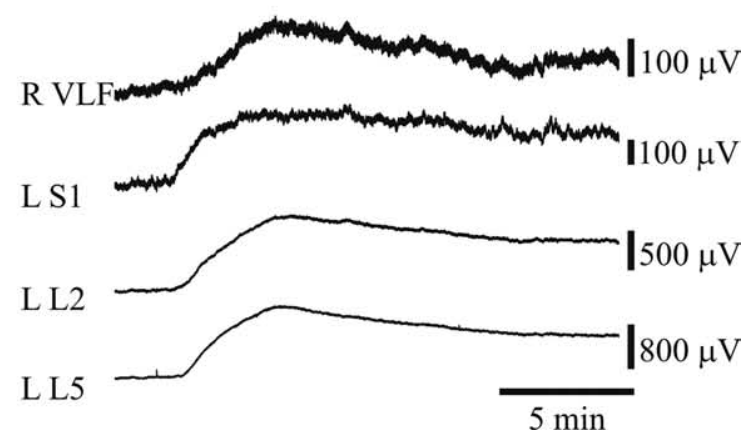

Figure 1. DA depolarizes motoneurons and interneurons projecting into the VLF. $A$, Neurograms show reflex responses evoked in the left $L 5$ ventral root (VR) after a single stimulus to the left $L 5$ dorsal root (DR) before and after bath application of blockers of fast glutamatergic and inhibitory transmission (see Materials and Methods). $\boldsymbol{B}$, Schematic illustrates the recording arrangement. $\boldsymbol{C}$, Neurogram recordings from ventral roots or white matter (VLF, L2, L5, and S1) indicate that DA can depolarize populations of motoneurons and interneurons. Neurogram recording from the ventral funiculus shows that DA depolarizes interneurons that project into this tract. Recordings were obtained in DC mode and low-pass filtered to isolate slow potentials. L, Left; $R$, right. 
A Control

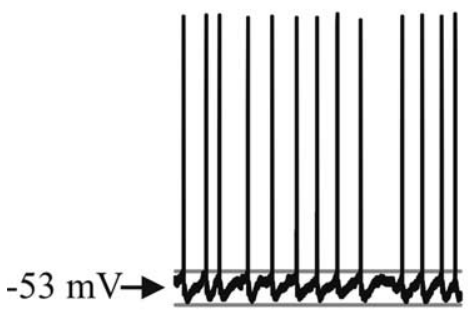

B

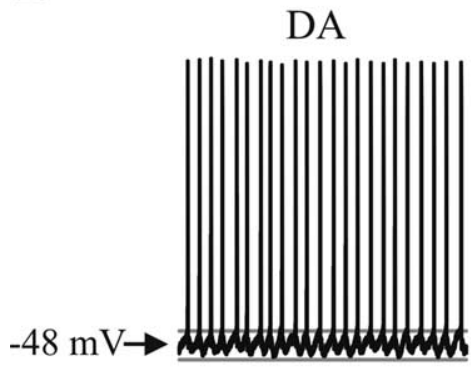

$\mathrm{C}$

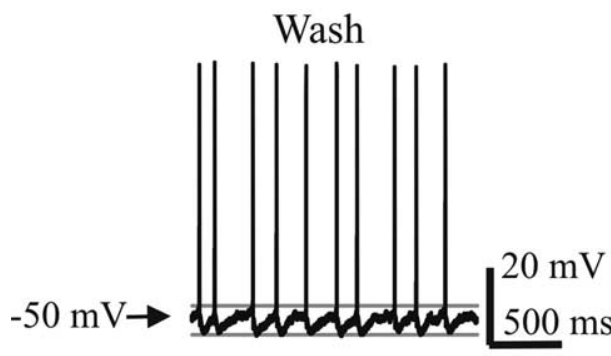

$\mathrm{D}$

$\mathrm{E}$

F
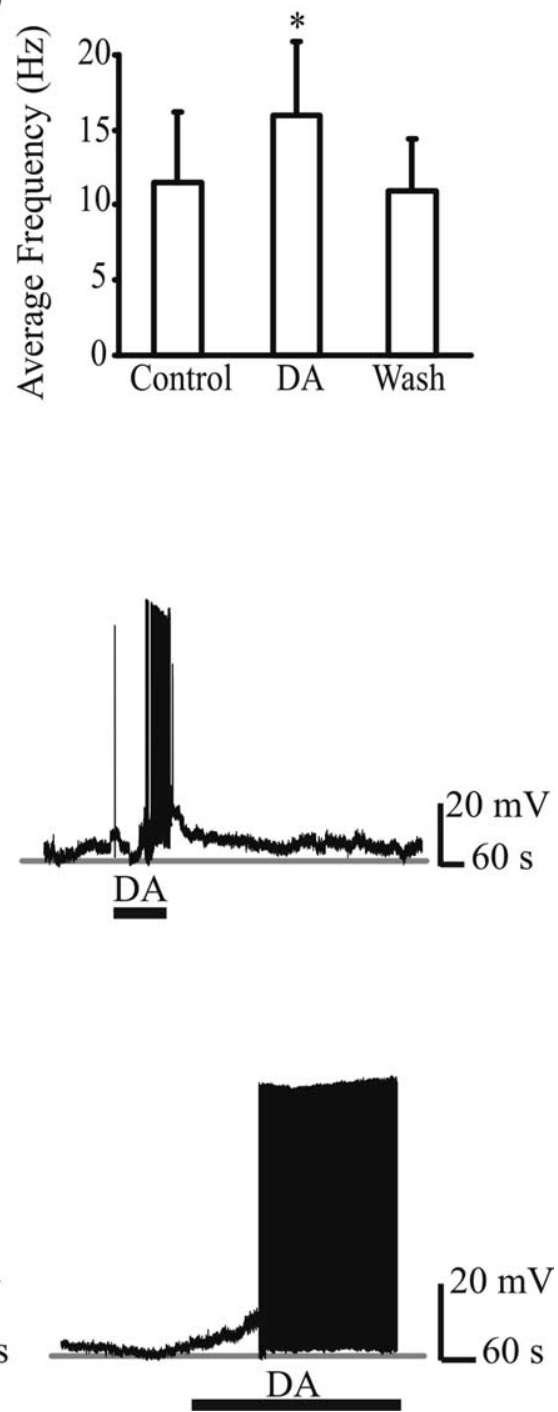

Figure 2. DA depolarizes motoneurons and increases the spike frequency. $A$, A representative cell showing spontaneous firing $\boldsymbol{B}$, The same representative cell shown in $\boldsymbol{A}$ after bath application of DA (100 $\mu \mathrm{m})$. Note the increase in spike frequency. $\boldsymbol{C}$, The effects of DA were reversed after washout. $\boldsymbol{D}$, Bar plots show mean changes in average spike frequency. ${ }^{*} p<0.05$ indicates a significant statistical difference (repeated-measures ANOVA; $n=6$ ). $\boldsymbol{E}$, A representative cell resting below threshold was depolarized by DA to spike threshold, which was reversed after washout. $\boldsymbol{F}$, Another cell showing the spiking pattern when DA was applied for a longer period.

servations (Fig. 1) (our unpublished observations). After washout of DA, spiking ceased and the membrane potential returned to more negative values. After a prolonged application of DA, spiking continued as long as the DA was present (Fig. 2 F).

\section{Dopamine increases the $f-I$ slope of motoneurons}

The increases in spike frequency could be caused by DA modulation of a combination of synaptic transmission and intrinsic motoneuronal properties. To target intrinsic properties of TS motoneurons affected by DA, we blocked fast glutamatergic and inhibitory neurotransmission (see Materials and Methods). Cells were held at $-72 \mathrm{mV}$ by injecting hyperpolarizing bias current. To generate $f-I$ plots, we administered a series of depolarizing current steps before and after bath applying DA. DA dramatically increased the spike frequency of TS motoneurons (Fig. 3A), resulting in a significant increase in the slope of the $f-I$ relationship from 107.6 $\pm 18.1 \mathrm{~Hz} / \mathrm{nA}$ (control) to $134.2 \pm 14.2 \mathrm{~Hz} / \mathrm{nA}$ (DA,
$29 \%$ increment), which returned to $108.1 \pm 11.3 \mathrm{~Hz} / \mathrm{nA}(2 \%$ higher than control) after washout $(n=17 ; p<0.05)$ (Fig. $3 B, C)$. In addition, DA significantly increased TS motoneuron input resistance from $113.5 \pm 5.5 \mathrm{M} \Omega$ (control) to $152.4 \pm$ 8.5 $\mathrm{M} \Omega$ (DA, 34\% increase), which was reduced to $120.5 \pm 6.1 \mathrm{M} \Omega(5 \%$ higher than control) after washout $(n=17 ; p<$ 0.05) (Fig. 3D). Consistent with the increase in input resistance, the rheobase (tested with increasing current steps) was reduced from $67.4 \pm 4.4 \mathrm{pA}$ (control) to $59.1 \pm 5.7 \mathrm{pA}(\mathrm{DA})(n=8 ; p<0.05)$. The spike threshold was significantly reduced by an average of $5.2 \mathrm{mV}(p<0.05)$.

\section{Dopamine partly increases spike frequency by reducing the afterhyperpolarization}

Although a change in input resistance would be expected to increase the spike frequency, other mechanisms could contribute. $\mathrm{SK}_{\mathrm{Ca}}$ channels (Bond et al., 2005) decrease the medium-duration afterhyperpolarization (mAHP), causing an increase in spike frequency in mouse motoneurons (Miles et al., 2005). Thus, we examined whether DA could modulate the $\mathrm{mAHP}$. At a holding potential of $-72 \mathrm{mV}$, depolarizing pulses (500 pA, 2 ms) were applied to evoke a single spike along with an mAHP. The amplitude of the MAHP was reversibly depressed after administration of DA (Fig. 4A). The absolute value of the mAHP ( $\mathrm{mAHP}$ ) was significantly depressed from $3.8 \pm 0.7 \mathrm{mV}$ (control) to $2.3 \pm 0.4 \mathrm{mV}$ (DA, $41 \%$ depression; $n=6$; $p<0.05)$, which partially recovered to $2.9 \pm 0.5 \mathrm{mV}$ after washout (Fig. $4 B$ ). The partial recovery was not significantly different from either the control or DA condition. We ran a series of control experiments to check whether the decrease in the AHP was a time-dependent effect. Without addition of DA, the AHP was stable over a similar experimental timeframe. Similar to previous reports (Miles et al., 2005), bath application of the apamin abolished the mAHP $(0.040 \pm 0.012 \mathrm{mV}$, apamin) (Fig. $4 C)$. Consistent with other reports, we did not observe that apamin significantly altered the input resistance at subthreshold levels (Martin-Caraballo and Greer, 2000). The mAHP was essentially abolished in the presence of apamin, and, not surprisingly, DA had no additional effect when added to the bath (mean mAHP amplitude: $3.56 \pm 0.34 \mathrm{mV}$, control; $0.040 \pm$ $0.012 \mathrm{mV}$, apamin; $0.043 \pm 0.007 \mathrm{mV}$, apamin and DA) (Fig. $4 D)$. Similar to DA, apamin increased the average spike frequency. Bath application of DA in the presence of apamin had no additional effect on spike frequency (Fig. $4 E$ ). Consistent with a previous report (Miles et al., 2005), apamin dramatically increased the $f-I$ slope from $116.3 \pm 17.2 \mathrm{~Hz} / \mathrm{nA}$ (control) to $204.1 \pm 24.5 \mathrm{~Hz} / \mathrm{nA}$ (apamin, $82 \%$ increment) (Fig. $4 F$ ), and no additional increase was observed after addition of 


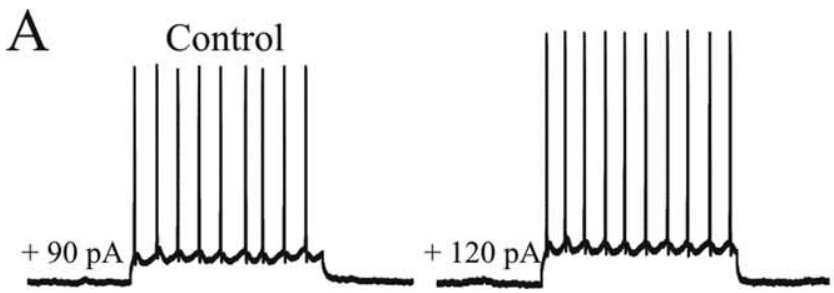

DA

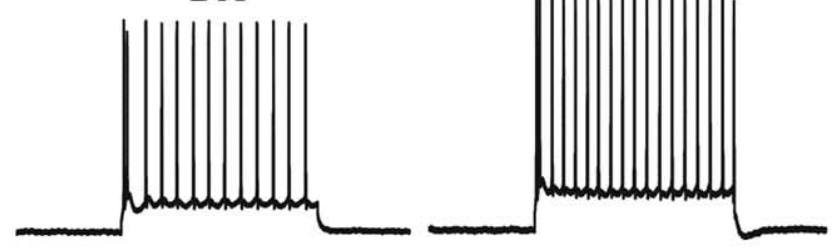

Wash

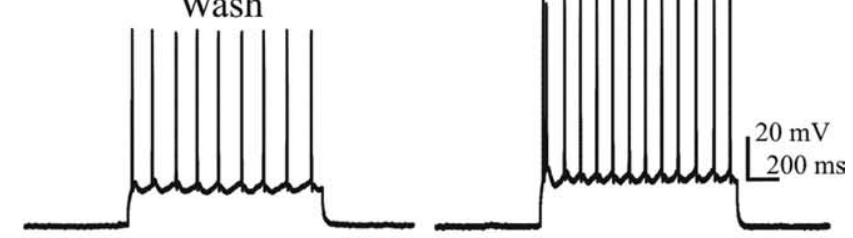

B

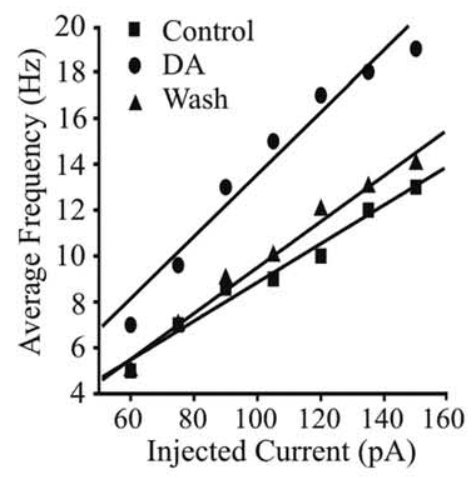

C

D
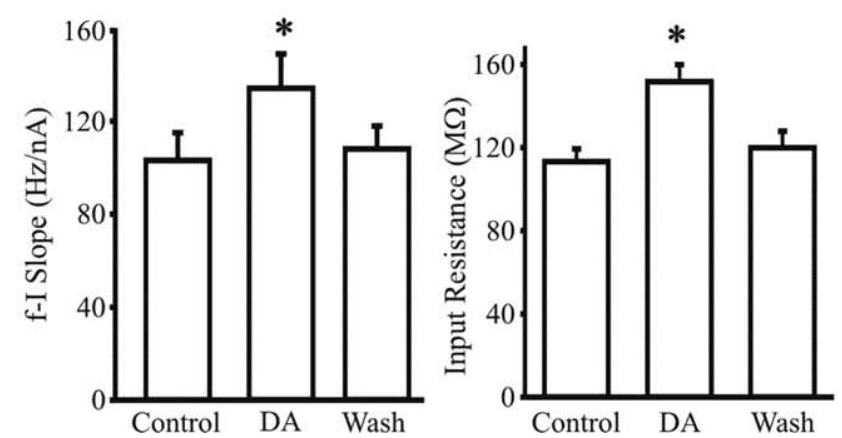

Figure 3. DA increases the intrinsic excitability of motoneurons. $A, D A$ increases spike frequency after step current injections (1.2 s steps; $90 \mathrm{pA}$, left column; $120 \mathrm{pA}$, right column). $\boldsymbol{B}, f-I$ plots obtained from the representative cell in $\boldsymbol{A}$. DA (circles) increases the average frequency compared with control (squares) or washout (triangles). C, D, Bar plots summarizing $f-/$ slope $(\boldsymbol{C})$ and input resistance $(\boldsymbol{D}) .{ }^{*} p<0.05$ indicates statistical significance (ANOVA; $n=17$ ). Inhibitory and glutamatergic blockers were used to suppress fast synaptic transmission (for details, see Materials and Methods).

DA $(201.6 \pm 26.3 \mathrm{~Hz} / \mathrm{nA} ; n=6 ; p<0.05)$ (Fig. $4 G)$. Collectively, our data suggest that DA is likely modulating apaminsensitive $\mathrm{SK}_{\mathrm{Ca}}$ channels to increase the spike frequency and the $f-I$ slope.
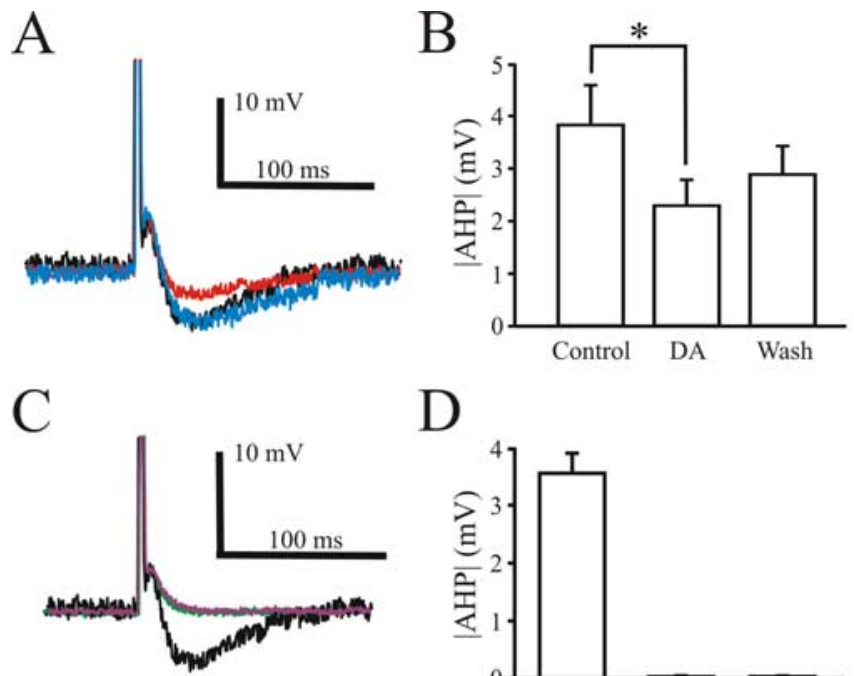

D
$\mathrm{E}$
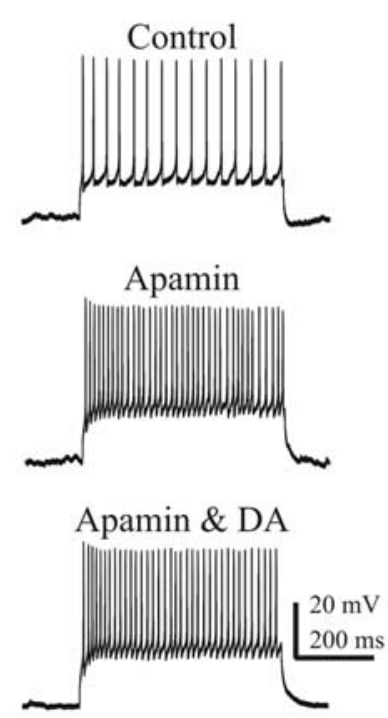

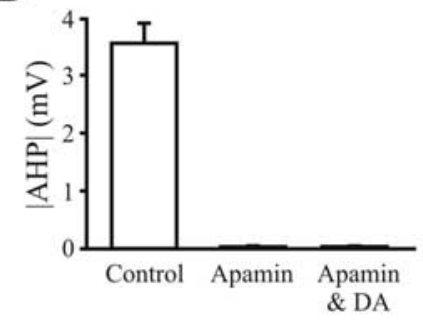

F

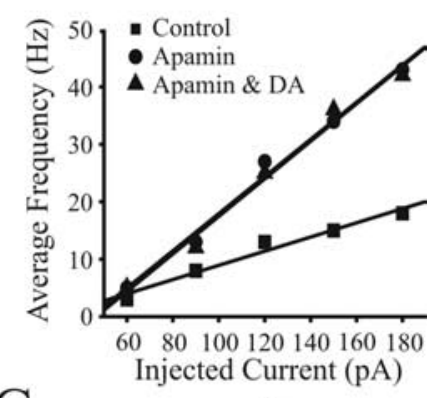

G

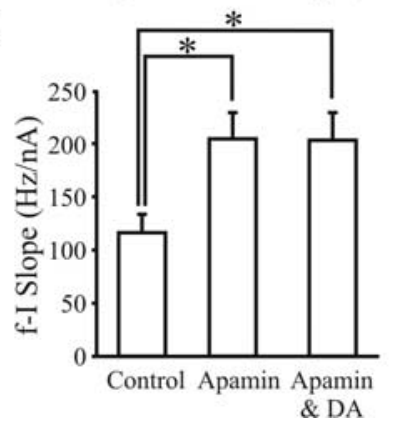

Figure 4. DA reduces the amplitude of the spike mAHP, leading to an increase in the $f-I$ slope. $A$, A representative cell showing mAHP after a single spike evoked by a brief current pulse in control (black trace), DA (red trace), and washout (blue trace) conditions. Note that DA reduces the mAHP amplitude. $B$, Summary plot shows that DA significantly reduces the absolute $\operatorname{mAHP}$ ( $p<0.05$, repeated-measures ANOVA), but the partial washout was not significantly different from either the control or DA. C, D, Apamin (100 nm, pink trace) eliminates $\operatorname{mAHP}(\boldsymbol{C}, \boldsymbol{D})$. DA (green trace) exerted no additional effect on mAHP after bath application of apamin. $\boldsymbol{E}$, A representative cell shows that apamin increases the spike frequency. $\boldsymbol{F}, f-I$ plot from the representative cell shown in $\boldsymbol{E}$. Note that apamin (circles) increases the $f-l$ slope compared with the control (squares). DA has no further effect on $f-/$ slope after bath application of apamin (triangles). G, Bar plot summarizes $f-/$ slope. ${ }^{*} p<0.05$ indicates statistical significance $(n=6)$. Inhibitory and glutamatergic blockers were used to suppress fast synaptic transmission (see Materials and Methods).

Dopamine decreases first-spike latency by reducing $I_{\mathrm{A}}$ Interestingly, DA reduced the first spike latency after a current step. The first spike latency was defined as the time between the onset of the current step and the peak of the first spike. In all 17 cells tested, DA reduced the first spike latency. However, this reduction was less apparent when the injected currents were high 
A.i.

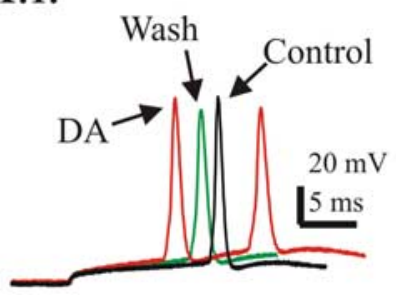

ii.

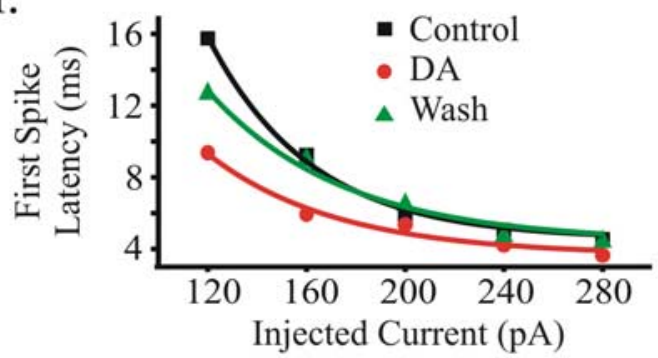

ii.

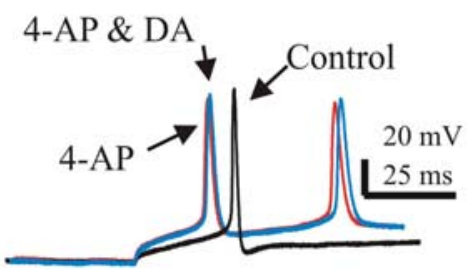

B.i.

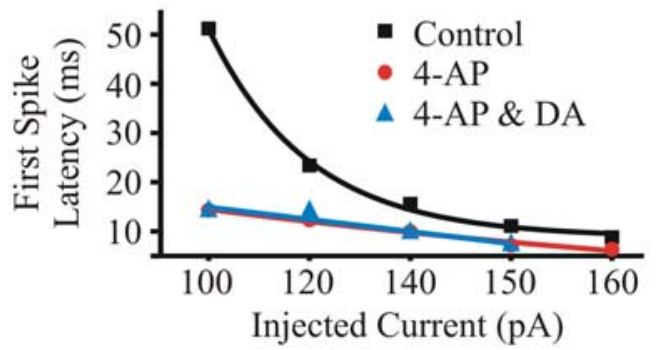

D

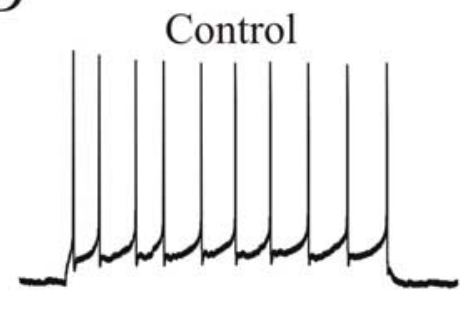

4-AP

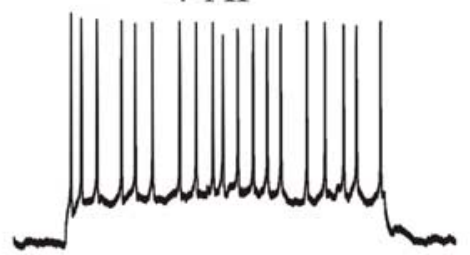

C.i.

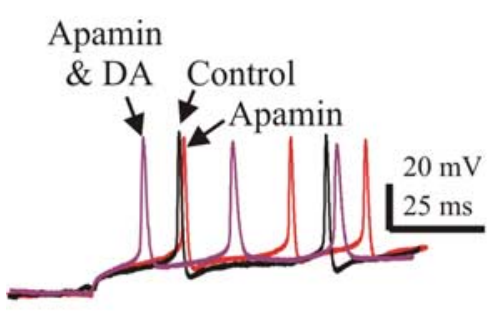

E

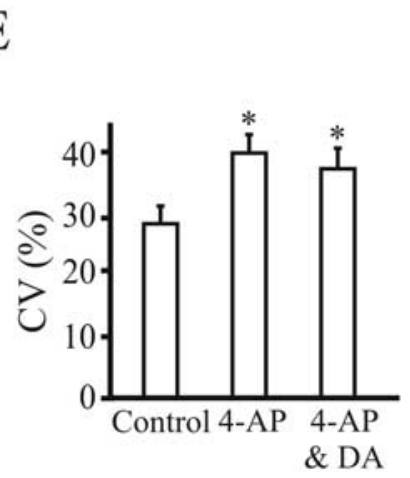

ii.

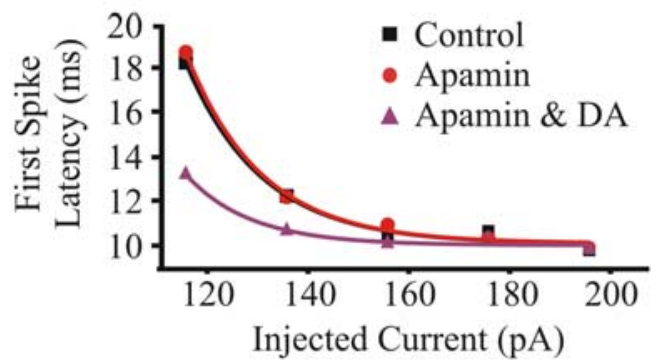

4-AP \& DA

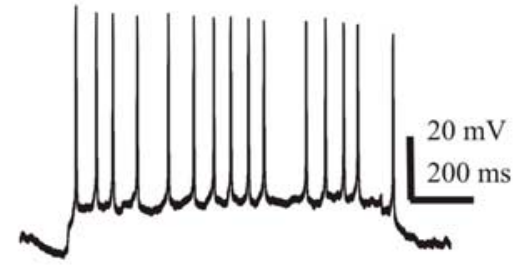

F

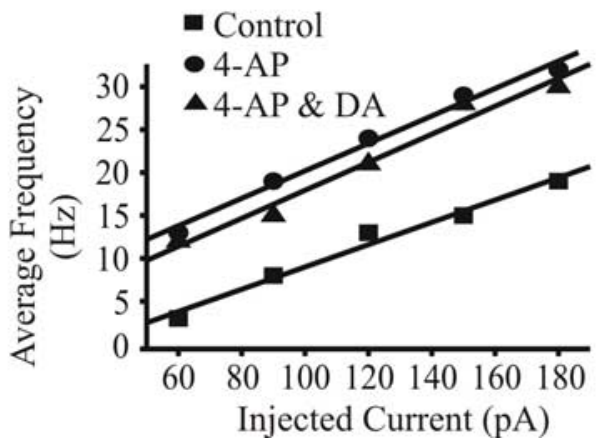

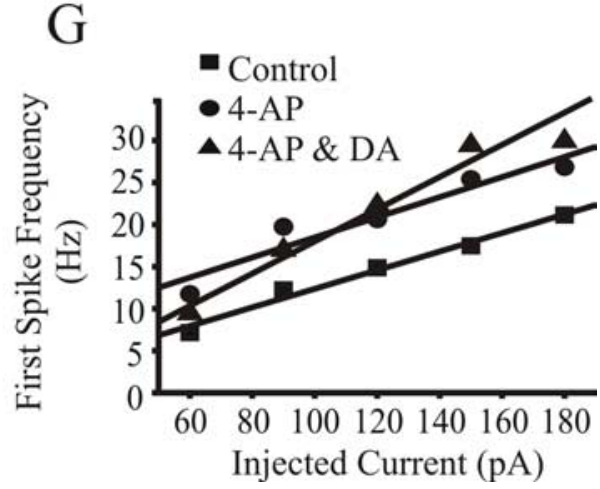

Figure 5. DA mimicked effects of 4-AP by reducing the first spike latency and increasing spike frequency. Ai, A representative cell shows the latency of the first spike after a depolarizing current step (120 pA) in control (black trace), DA (red trace), and washout (green trace) conditions. Aii, Spike latency is plotted against the injected currents. Bi, A representative cell shows the latency of the first spike after a depolarizing current pulse (120 pA) in control (black trace), 4-AP (red trace), and 4-AP plus DA (blue trace) conditions. Bii, Spike latency is plotted against the injected currents. Ci, Representative traces show the latency of first spike in control (black trace), apamin (red trace), and apamin plus DA (pink trace). Cii, Spike latency is plotted against the injected currents. For Aii, Bii, and $\boldsymbol{C i i}$, the data were fitted with single-exponential curves. $\boldsymbol{D}, 4$-AP increases the spike frequency of a representative cell. $\boldsymbol{E}$, CV of the ISI indicates that 4 -AP decreases spike regularity ( $n=8$; $p<$ 0.05). $\boldsymbol{F}$, Average frequency $f-I$ plot from the cell shown in $\boldsymbol{D}$. $\boldsymbol{G}$, First spike instantaneous frequency $f-I$ plot from $(\boldsymbol{F})$. Inhibitory and excitatory blockers were used to suppress fast synaptic transmission (see Materials and Methods).

(Fig. 5A). Changes in first spike latency that we observed are typically attributable to the modulation of low-threshold, fastinactivating (4-AP-sensitive, $\mathrm{I}_{\mathrm{A}}$ ) $\mathrm{K}^{+}$currents (Nisenbaum et al., 1994; Schoppa and Westbrook, 1999). Indeed, a similar reduction in first spike latency occurred after bath application of 4-AP (Fig. 5Bi,Bii). Applying DA after the administration of 4-AP did not shorten the first spike latency compared with 4-AP alone (Fig.
$5 B i, B i i)$. In contrast, apamin alone did not shorten the first spike latency, although not surprisingly the successive interspike intervals were reduced (Fig. 5Ci). Apamin did not occlude the effect of DA on first spike latency (Fig. $5 \mathrm{Ci}, \mathrm{Cii}$ ), confirming that the modulation of first spike latency is not mediated by the $\mathrm{SK}_{\mathrm{Ca}}$ channel but by the 4-AP sensitive $\mathrm{K}^{+}$channel. Similar to DA, 4-AP increased the spike frequency, and a combination of 4-AP and DA 
did not further increase spike frequency (Fig. 5D). Unlike DA, however, 4-AP makes the firing patterns irregular (Fig. 5D). CV for the ISI was $28.4 \pm 2.8$ in control, $39.9 \pm 1.9$ in 4 -AP only $(45 \%$ increment), and $37.4 \pm 3.3$ in 4 -AP plus DA (32\% increment; $p<$ $0.05 ; n=8$ ) (Fig. $5 E$ ). Although 4-AP did shift the average frequency $f-I$ relationship to the left, we did not observe an increase in the average frequency $f-I$ slope $(118.5 \pm 12.7 \mathrm{~Hz} / \mathrm{nA}$, control; $126.3 \pm 12.2 \mathrm{~Hz} / \mathrm{nA}, 4$-AP; $n=8 ; p>0.05$ ) (Fig. $5 F$ showed a representative plot). DA had no additional effect on average frequency $f-I$ slope with $4-\mathrm{AP}$ in the bath $(124.8 \pm 14.1 \mathrm{~Hz} / \mathrm{nA} ; n=$ $8 ; p>0.05)$. However, DA still had some minor residual effect on ISI, because the first ISI was reduced by $17 \%$ compared with when DA was added in the presence of 4 -AP. This residual effect on ISI was manifest when the first-spike frequency $f-I$ was plotted (Fig. $5 G$ ).

\section{Dopamine increases excitatory synaptic transmission}

It is well known that DA modulates synaptic transmission in other areas of the brain so we tested whether this held true for spinal motoneurons. Because DA increases excitability in spinal motoneurons, we decided to concentrate on glutamatergic transmission. We first isolated the sEPSCs by bath applying inhibitory synaptic blockers (strychnine and picrotoxin). The membrane potential was clamped to $-82 \mathrm{mV}$ to minimize NMDA currents. Bath application of DA increased the frequency $(12.8 \pm 0.5 \mathrm{~Hz}$, control; $16.1 \pm 0.6 \mathrm{~Hz}, \mathrm{DA}, 19 \%$ increment; $n=8 ; p<0.05)$ and amplitude $(69.8 \pm 14.1 \mathrm{pA}$, control; $98.4 \pm 18.2 \mathrm{pA}, \mathrm{DA}, 45 \%$ increment; $n=8 ; p<0.05$ ) of sEPSCs (Fig. $6 A$ ). AP-5 and CNQX were bath applied at the end of the experiments and abolished all sEPSCs.

To isolate the DA-mediated increases in glutamatergic transmission from premotor interneurons to motoneurons, we added TTX in the presence of the inhibitory blockers and measured mEPSCs. Again, the membrane potential was clamped to -82 $\mathrm{mV}$ to minimize NMDA currents. DA increased mEPSC frequency from $12.8 \pm 1.2 \mathrm{~Hz}$ (control) to $15.6 \pm 1.3 \mathrm{~Hz}$ (DA, 23\% increment; $n=6 ; p<0.05$ ) (Fig. $6 B$ ). On average, DA increased mEPSC amplitude from $35.2 \pm 6.4 \mathrm{pA}$ (control) to $42.5 \pm 7.8 \mathrm{pA}$ ( $21 \%$ increment with DA; $n=6 ; p<0.05$ ) (Fig. 6B). To further test for postsynaptic effects, we applied puffs of AMPA (one puff every minute), before, during, and after washout of bath-applied DA, using previously published protocols (Sharifullina et al., 2004). To reduce space clamp concerns and block $\mathrm{K}^{+}$conductances, we added $\mathrm{Cs}^{+}$to the intracellular pipette solution. Under control conditions, the AMPA puff elicited a robust whole-cell inward current in all cells $(n=5$; peak amplitude $153 \pm 12 \mathrm{pA}$; decay time constant, $4.70 \pm 0.80 \mathrm{~s}$ ) (Fig. $7 \mathrm{~A}$ ). Bath application of DA ( $5 \mathrm{~min}$ ) was followed by a progressive increase in the AMPA current amplitude (peak amplitude, $181 \pm 21 \mathrm{pA}$; 19\% increment; $p<0.05$ ) (Fig. 7 $A, C, E$ ) and also in the decay time constant (time constant, $7.44 \pm 1.27$ s; $56 \%$ increment; $p<0.05$ ) (Fig. $7 B, D, F)$. After washout, the current amplitude and time constant returned to control conditions ( $p>0.05$ for both).

\section{Dopamine is necessary but not sufficient to evoke rhythms in} Hb9 neurons

Our population recordings (Fig. 1) suggest that DA can depolarize populations of ventral interneurons. DA modulates the timing and stability of spinal locomotor outputs, meaning that it must modulate interneurons in central-pattern-generating circuits (Kiehn and Kjaerulff, 1996; Jiang et al., 1999b; Whelan et al., 2000; Barriere et al., 2004). Hb9 interneurons exhibit electrophysiological signatures (Hinckley et al., 2005b; Wilson et al.,
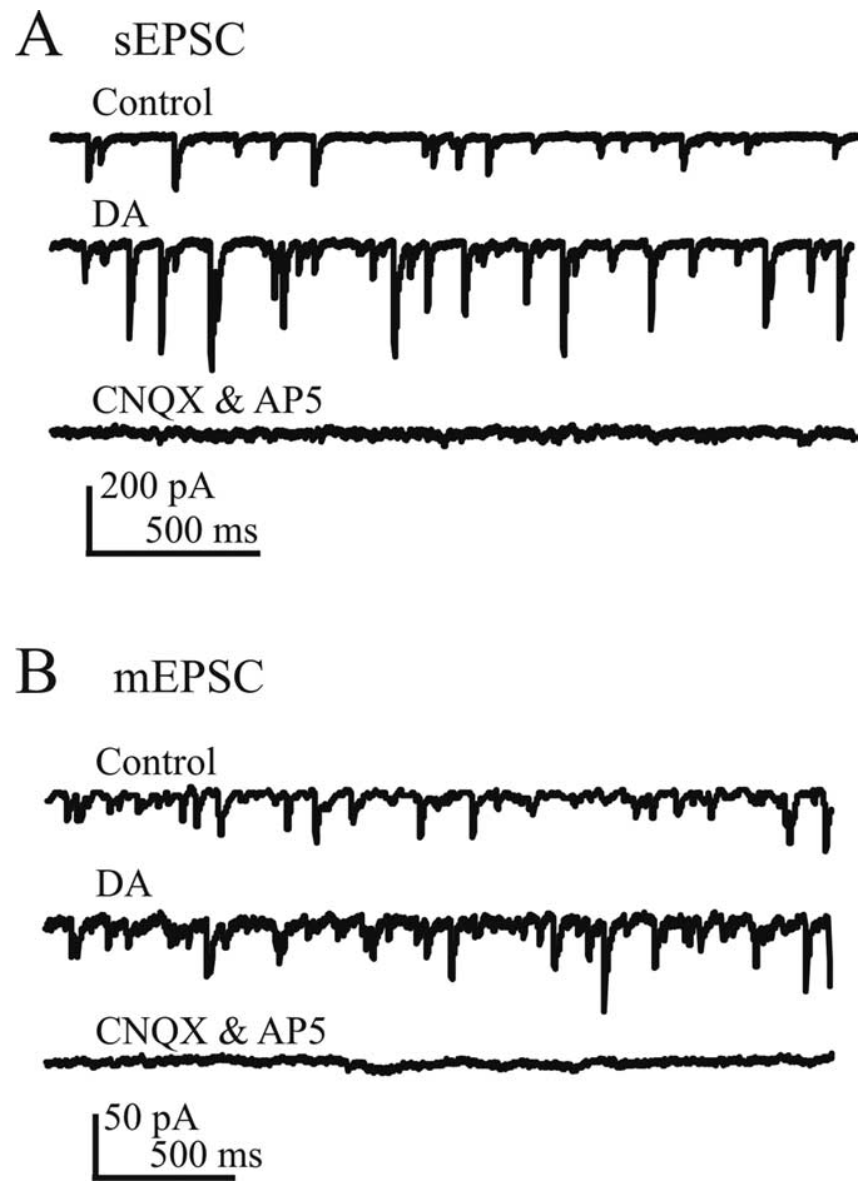

Figure 6. DA increases the amplitude and frequency of spontaneous and miniature EPSCs. $A$, sEPSC. Representative trace $\left(V_{h}\right.$ of $\left.-82 \mathrm{mV}\right)$ in control (top trace), DA (middle trace), and in the presence of $C N Q X$ and $A P-5$ (bottom trace). Strychnine and picrotoxin were included in the bath solution. $B$, mEPSC. Inhibitory synaptic blockers strychnine and picrotoxin and the sodium channel blocker TTX were included in the bath solution. Representative trace showing miniature EPSC $\left(V_{h}\right.$ of $\left.-82 \mathrm{mV}\right)$ in control (top trace), DA (middle trace), and in the presence of AP- 5 and CNQX (bottom trace). For statistics, see Results.

2005) that indicate a direct role as rhythm-generating interneurons, and we therefore used these cells to examine the rhythmogenic capabilities of DA at a cellular level. Hb9 cells are most likely glutamatergic cells, and, consistent with previous reports (Hinckley et al., 2005b), we recorded from $\mathrm{GFP}^{+}$cells located in lamina VIII with a characteristic bipolar morphology and an average input resistance of $762 \pm 215 \mathrm{M} \Omega(n=68)$.

Although spontaneous oscillations have been reported using whole spinal cord preparations (Hinckley et al., 2005b), we did not observe such activity in our slice preparation (Fig. $8 A, B$, control). In the first set of experiments, we elicited oscillatory bursting after administration of NMDA $(20 \mu \mathrm{M}), 5-\mathrm{HT}(20 \mu \mathrm{M})$, and DA $(20 \mu \mathrm{M})$ in 18 of $32 \mathrm{GFP}^{+}$cells. $\mathrm{GFP}^{+}$cells either spiked tonically or were silent (depending on membrane voltage) with bath application of NMDA $(20 \mu \mathrm{M})$ and 5-HT $(20 \mu \mathrm{M})$. Only after subsequent addition of DA (20 $\mu \mathrm{M}$ NMDA, $20 \mu \mathrm{M}$ 5-HT, and $50 \mu \mathrm{M} \mathrm{DA})$ did an oscillatory bursting pattern emerge $(n=$ 10 of 18). However, DA $(50 \mu \mathrm{M})$ applied alone was not sufficient to induce such a pattern; only after NMDA $(20 \mu \mathrm{M})$ and 5-HT (20 $\mu \mathrm{M})$ were included together with DA did we observe oscillations $(n=8$ of 18$)$ (Fig. $8 B$ ). The oscillatory patterns were examined over a defined range of voltage levels $(-50$ to $-90 \mathrm{mV})$ in 11 of 18 cells. At depolarized potentials, the bursting pattern was not ob- 
A

B

Control DA Wash Blockers
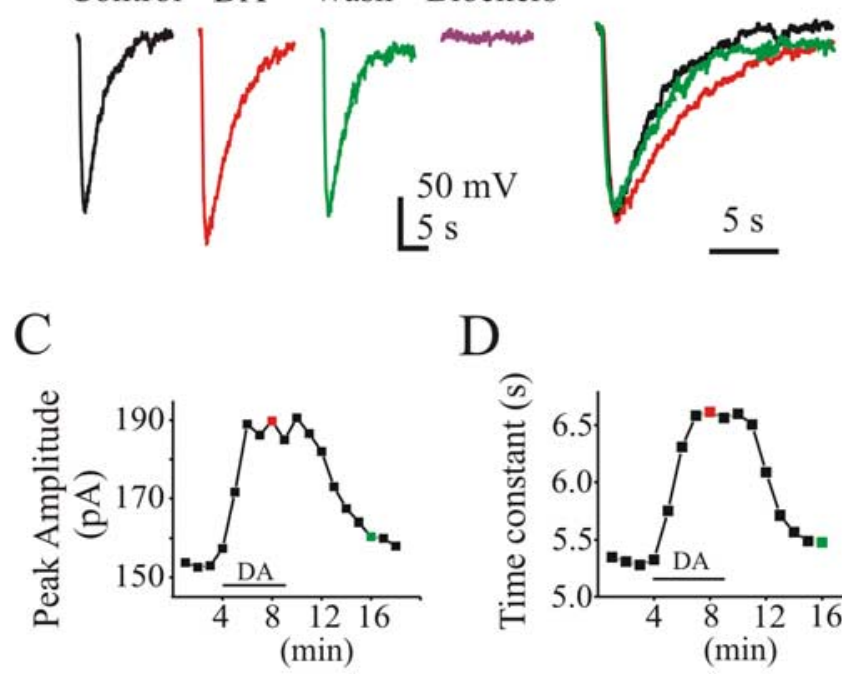

$\mathrm{D}$

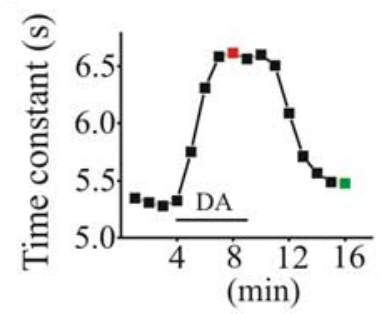

$\mathrm{E}$

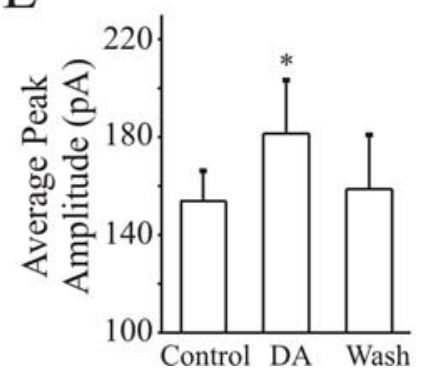

F

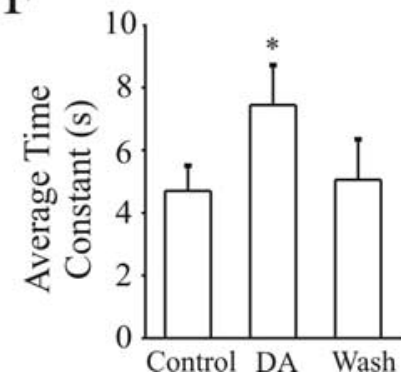

Figure 7. DA increases AMPA evoked currents. $A$, AMPA-evoked whole-cell currents $\left(V_{h}\right.$, $-82 \mathrm{mV}$ ) in control (black trace), DA (red trace), washout (green trace), and CNQX (blue trace). $\boldsymbol{B}$, Normalized traces from $\boldsymbol{A}$. Notice that DA prolongs the whole-cell currents. $\boldsymbol{C}$ and $\boldsymbol{D}$ show the changes of AMPA current peak amplitude and decay time constant before, during, and after DA perfusion (the representative cell shown in $A$ ). The data points corresponding to traces shown in $\boldsymbol{A}$ were highlighted in colors. $\boldsymbol{E}, \boldsymbol{F}, \mathrm{DA}$ increases the average peak current amplitude $(\boldsymbol{E})$ and prolongs decay time constant $(\boldsymbol{F}) .{ }^{*} p<0.05 . \mathrm{K}^{+}$currents were blocked by addition of $\mathrm{Cs}^{2+}$ in the intracellular pipette solution.

vious because of repetitive firing, whereas hyperpolarizing the cell at approximately $-90 \mathrm{mV}$ abolished rhythmic oscillations (Fig. $8 A, B$, third column). In between, the oscillations were regular and sustainable. In all cells, the cycle period decreased as the cells depolarized (Fig. 8C), evident as a decrease in the interburst period. However, the intraburst bursting duration ("up" time) slightly increased as the cells depolarized. Thus, the up/down ratio increased after depolarization (Fig. 8C).

GFP-labeled cells from $\mathrm{Hb} 9$ mice were reported to be heterogeneous with at least two distinct groups identified as type I $\left(\mathrm{Hb}^{+} / \mathrm{GFP}^{+}\right)$and type II (Hb9-negative/GFP ${ }^{+}$) interneurons with distinct electrophysiological signatures (Wilson et al., 2005). We formulated a diagnostic look-up table (supplemental Table 1, available at www.jneurosci.org as supplemental material) and assigned a score to each of the published criteria ( -1 given to type I with $100 \%$ weight, +1 given to type II with $100 \%$ weight). For example, $30 \%$ of type I cells showed spontaneous firing, whereas $100 \%$ type II cell fire spontaneously (Wilson et al., 2005). Therefore, if a cell does not fire spontaneously, it can be judged to be a type I (given a score - 1). If a cell fires spontaneously, it is more likely to be a type II than type I, so the score would be +0.6 [score $=$ type II $(100 \%)-$ type I $(30 \%)]$. The scores from all the
A

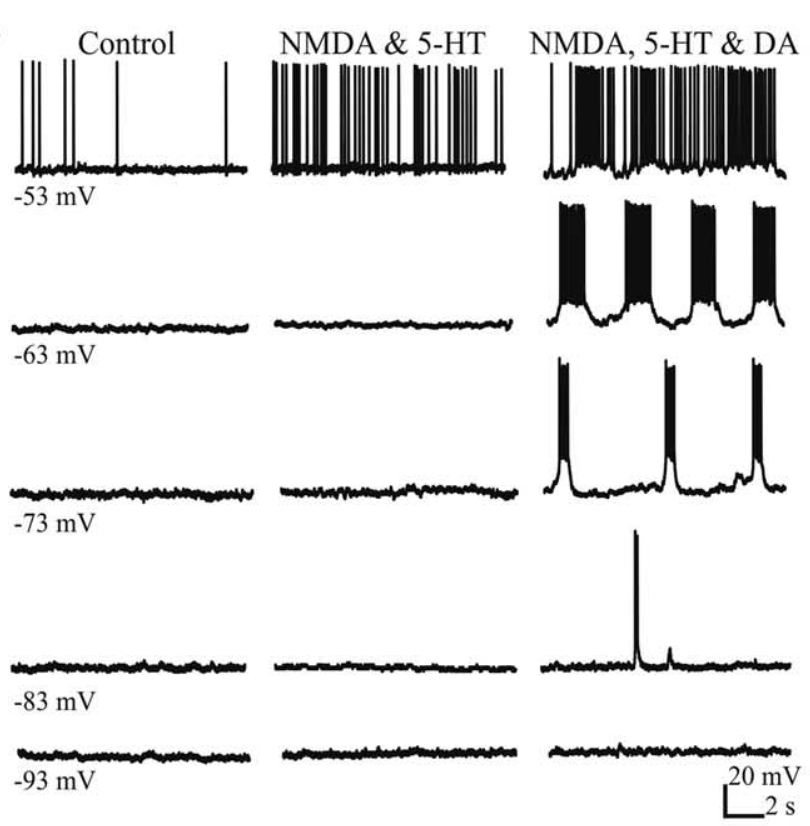

B
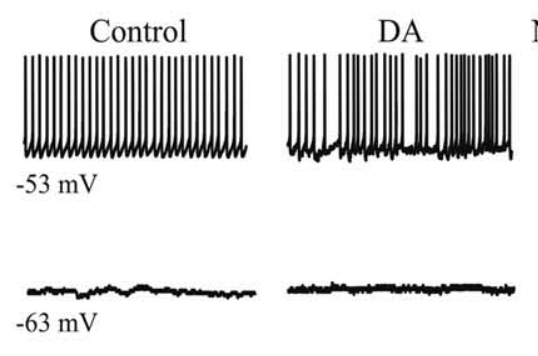

NMDA, 5-HT \& DA
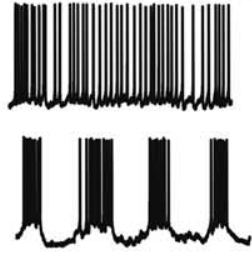

$-73 \mathrm{mV}$
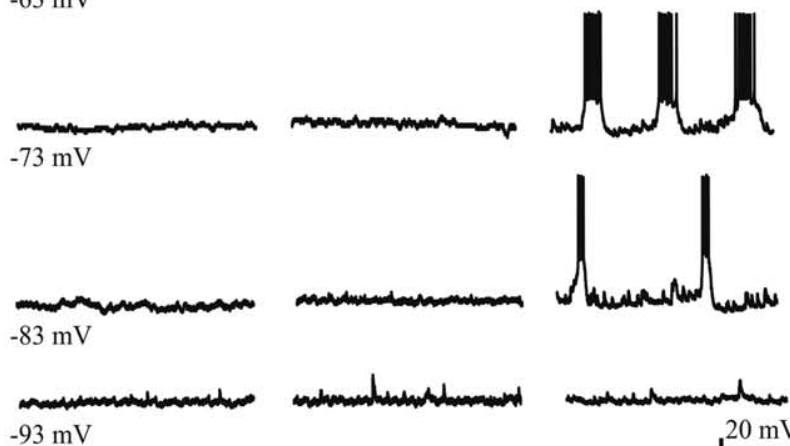

$-93 \mathrm{mV}$

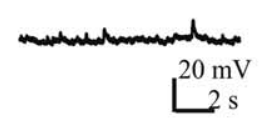

C
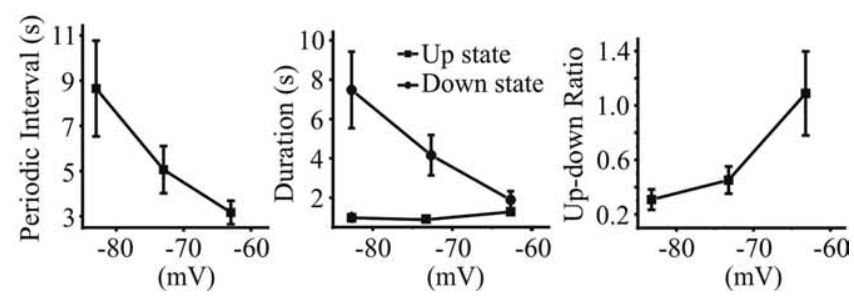

Figure 8. DA is a necessary but not sufficient part of the drug mixture (NMDA, DA, and 5-HT) that can evoke oscillatory activity of GFP ${ }^{+}$interneurons in $\mathrm{Hb} 9 / \mathrm{GFP}$ mice. $A$, A representative cell (type I, $\mathrm{Hb}^{+} / \mathrm{GFP}^{+}$) exhibited either no spiking or continuous spiking after bath application of NMDA $(20 \mu \mathrm{M})$ and $5-\mathrm{HT}(20 \mu \mathrm{M})$. Addition of NMDA $(20 \mu \mathrm{M}), 5-\mathrm{HT}(20 \mu \mathrm{M})$, and DA (50 $\mu \mathrm{m}$ ) evoked rhythmic bursting from this cell. $\boldsymbol{B}$, A representative cell showed either no spikes or tonic spiking in DA only but showed rhythmic bursting activity in the presence of NMDA (20 $\mu \mathrm{M}), 5-\mathrm{HT}(20 \mu \mathrm{M})$, and DA $(50 \mu \mathrm{m})$. C, The cycle period of the oscillations was voltage depen$\operatorname{dent}(n=11)$. 
A

TTX, NMDA \& 5-HT

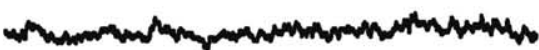

$-63 \mathrm{mV}$

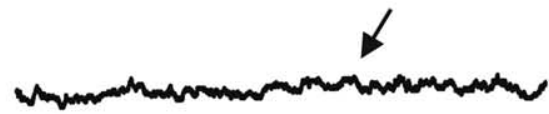

$-73 \mathrm{mV}$

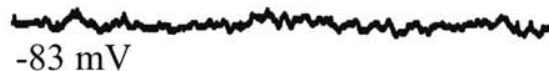

B

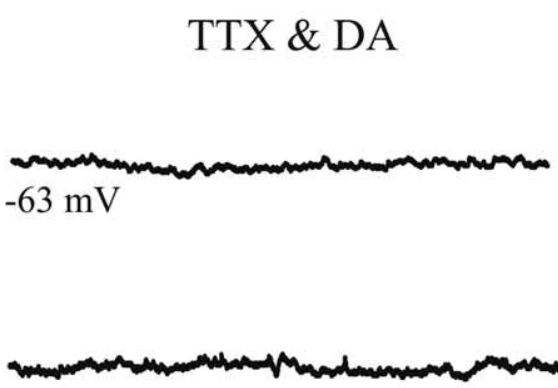

$-73 \mathrm{mV}$

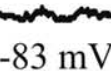

TTX, NMDA, 5-HT \& DA
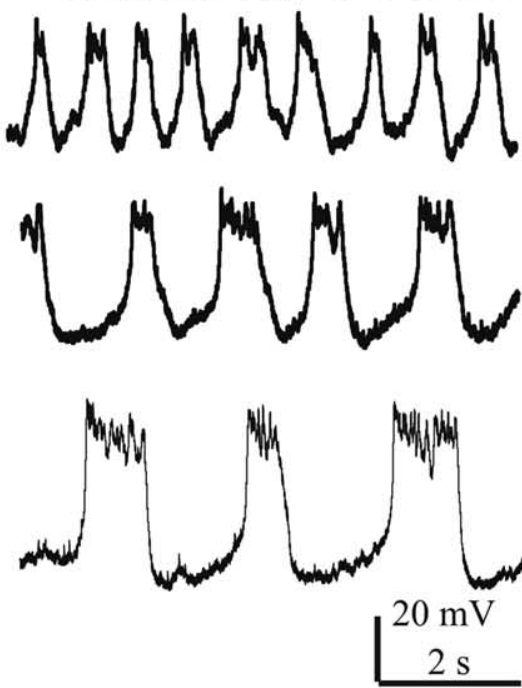

TTX, NMDA, 5-HT \& DA
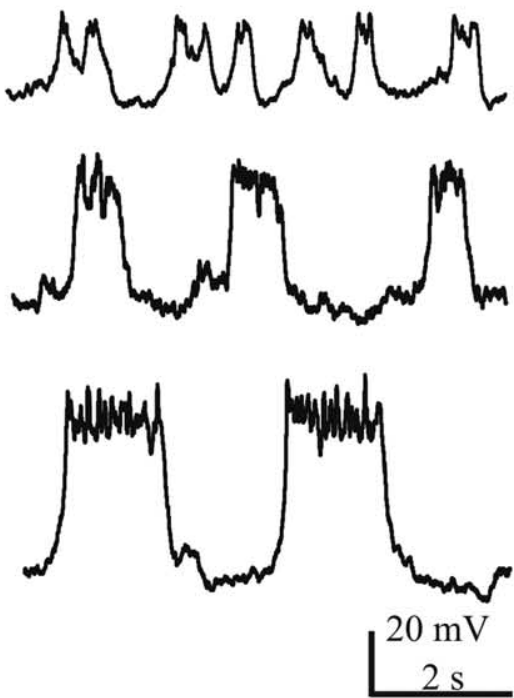
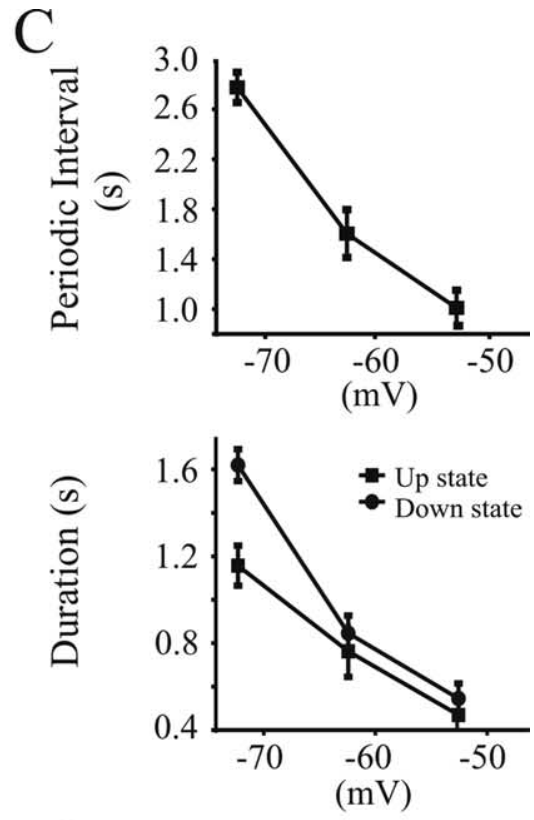

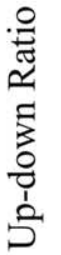

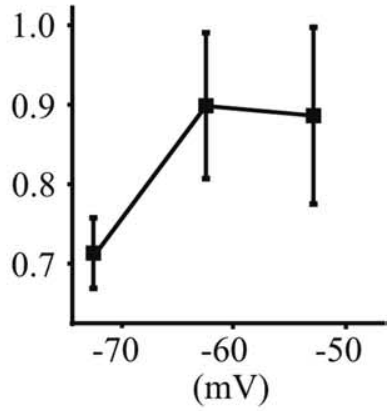

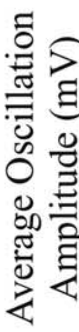

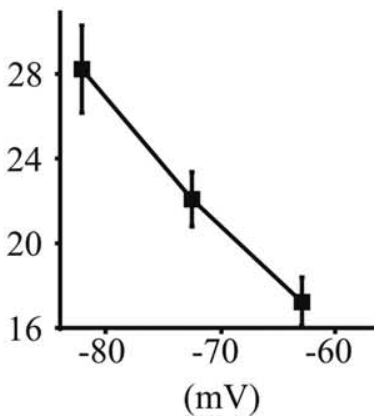

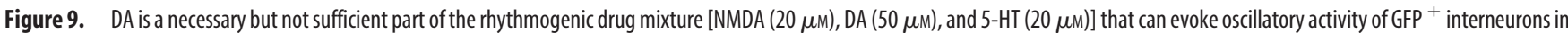
the presence of TTX $(1 \mu \mathrm{m})$. A, A representative cell (type I, Hb9 ${ }^{+} / \mathrm{GFP}^{+}$cells) that shows irregular fluctuations in membrane potential after bath application of NMDA (20 $\mu \mathrm{m}$ ) and 5-HT (20 $\mu \mathrm{m}$ ) (left column). Oscillatory activity was evoked after addition of DA (50 $\mu \mathrm{m}$ ) (right column). B, A representative cell after bath application of DA ( $50 \mu \mathrm{m}$ ) only does not induce oscillations (left column). The subsequent addition of NMDA (20 $\mu \mathrm{m})$ and 5-HT (20 $\mu \mathrm{m})$ produced oscillations (right column). $C$, The cycle period of the oscillations was voltage dependent $(n=8)$.

criteria were averaged to form the overall score of the cell. We defined that average scores between -1 and 0 were diagnostic of type I-like cells, whereas a score between 0 and +1 indicated a type II-like cell. This quantitative rating system categorized two distinct populations (see the histogram in supplemental Fig. 1, available at www.jneurosci.org as supplemental material). In 22 of 32 cells, we specifically ran a series of protocols to test those parameters listed in supplemental Table 1 (available at www. jneurosci.org as supplemental material) before superfusing 5-HT, NMDA, or DA. Rhythmic bursting could be elicited by 5 -HT $(20 \mu \mathrm{M})$, NMDA $(20 \mu \mathrm{M})$, and DA $(50 \mu \mathrm{M})$ in 7 of 13 type I-like interneurons and 4 of 9 type II-like interneurons, suggesting that the rhythmic bursting was not necessarily confined to
$\mathrm{Hb}^{+} / \mathrm{GFP}^{+}$cells $\left(\chi^{2}\right.$ test; type I and II; $\left.p>0.05\right)$. Together, DA appears to be necessary but not sufficient to induce and maintain rhythmic bursting within $\mathrm{GFP}^{+}$interneurons.

DA is necessary but not sufficient to evoke networkindependent cellular oscillation in Hb9/GFP interneurons Recently, $\mathrm{Hb}^{+} / \mathrm{GFP}^{+}$cells have been identified to have conditional oscillatory properties in the presence of DA, 5-HT, NMDA, and TTX (Wilson et al., 2005). We specifically tested whether DA was necessary to evoke rhythmicity in these cells. In the presence of NMDA $(20 \mu \mathrm{M}), 5$-HT $(20 \mu \mathrm{M})$, and TTX $(1 \mu \mathrm{M}), \mathrm{GFP}^{+}$ interneurons exhibited irregular voltage fluctuations of several millivolts (Fig. 9A, arrows). Oscillatory activity appeared only 
after DA $(50 \mu \mathrm{M})$ was added $(n=7)$ (Fig. 9A). Similarly, DA (50 $\mu \mathrm{M})$ alone did not induce oscillations; subsequent addition of 5-HT $(20 \mu \mathrm{M})$ and NMDA $(20 \mu \mathrm{M})$ were required to elicit oscillations $(n=9)$ (Fig. $9 B)$. In the presence of TTX and NMDA plus 5 -HT plus DA, 16 of 47 cells (34\%) were oscillatory. Similar to the previous set of experiments (Fig. 8), the average cycle period decreased as the cells were depolarized (8 of 16 cells) (Fig. 9C), but overall the cycle periods were relatively short. However, the up time on average decreased as the cells was depolarized. The reduction in the interburst interval was greater than the intraburst duration; thus, the up/down ratio still went up as the cells were depolarized (Fig. 9C). In addition, the average oscillation amplitude was reduced as the cells were depolarized (Fig. 9C). Similar to the Hb9 experiments without TTX, oscillatory activity was not exclusive to type I cells ( 5 of 15 type I cells and 3 of 8 type II cells showed oscillations). We performed a group of control experiments in which DA $(50 \mu \mathrm{M}), 5-\mathrm{HT}(20 \mu \mathrm{M})$, NMDA (20 $\mu \mathrm{M})$, and TTX $(1 \mu \mathrm{M})$ were bath applied together. In these experiments, we observed rhythmic oscillations in 8 of 35 cells $(23 \%)$. Overall, there were no qualitative differences in the characteristics of the oscillations. Together, these data suggest that DA is necessary but not sufficient to induce conditional oscillations in both type I and II interneurons.

\section{Discussion}

Our interest in DA actions on spinal circuits is primarily fueled by the effects it has on locomotor networks in which it enhances network stability and boosts the amplitude of motor output (Kiehn and Kjaerulff, 1996; Whelan et al., 2000; Barriere et al., 2004; Madriaga et al., 2004). Our work shows that DA increases excitability of motoneurons by acting on two potassium conductances, $\mathrm{SK}_{\mathrm{Ca}}$ and $I_{\mathrm{A}}$. We also demonstrate that DA is a critical element in evoking conditional oscillatory properties in $\mathrm{Hb} 9$ cells (Fig. 10).

\section{Intrinsic properties}

DA modulated several intrinsic properties, leading to an increase in motoneuronal gain. In motoneurons, the mAHP duration is important in setting the minimum steady-state spiking rate, whereas its amplitude and rate of postspike decline are important for setting the $f-I$ slope (Kernell, 2006). Conversely, spike frequency adaptation beyond the initial few spikes is not thought to be mediated by mAHP modulation (Miles et al., 2005). Our data demonstrate that DA reduces $\mathrm{MAHP}$ amplitude in motoneurons, leading to an increase in the $f-I$ slope, likely by affecting $\mathrm{SK}_{\mathrm{Ca}}$ conductances. Several lines of evidence support these conclusions. First, bath application of apamin almost completely blocked the mAHP, suggesting that $\mathrm{SK}_{\mathrm{Ca}}$ currents were responsible for the majority of modulatory effects. Second, DA did not further alter $f-I$ relationships when apamin was in the bath. Third, in experiments in which 5-HT or other synaptic blockers decreased the mAHP amplitude, the $f-I$ slope also increased, similar to our results (Hounsgaard et al., 1988; Wallen et al., 1989; Viana et al., 1993; Hultborn et al., 2004; Miles et al., 2005). In the lamprey, DA reduces the $\mathrm{mAHP}$ in spinal motoneurons (Schotland et al., 1995) by inhibition of N- and L-type calcium currents through activation of the $\mathrm{D}_{2}$ receptors (Wikstrom et al., 1999). However, it is likely that DA uses a different mechanism to modulate SK conductances in mammals because the excitatory effects of DA are primarily through $\mathrm{D}_{2}$ receptors in the lamprey (Schotland et al., 1995), whereas our work in the mouse (Madriaga et al., 2004) and others using the rat (Seth et al., 1993; Barriere et al., 2004) suggest that DA is likely acting through a $D_{1}$-mediated

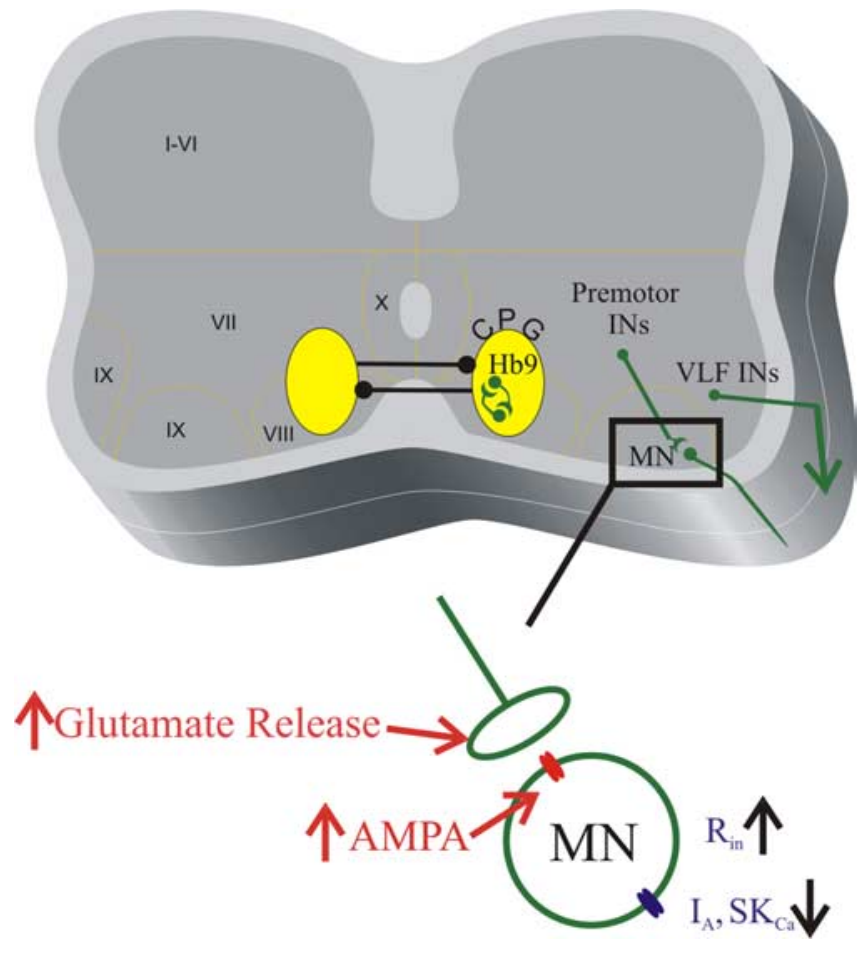

Figure 10. Schematic illustrating the modulatory effects of DA on intrinsic and synaptic properties. In the spinal cord schematic, the green cells are those in which we observed an excitatory effect. VLF neurons were recorded extracellularly, whereas the other cells were recorded using whole-cell patch techniques. DA was necessary to evoke conditional oscillations in $\mathrm{Hb} 9$ cells. Inset, DA has a variety of effects on motoneurons, increasing synaptic transmission and decreasing $I_{\mathrm{A}}$ and $\mathrm{SK}_{\mathrm{Ca}}$ currents.

system. Also in the mouse, L-type subunits expression gradually increases over the first 3 weeks (Jiang et al., 1999b), which again suggests a different mechanism for the actions of DA, perinatally. In contrast to pharmaceutical activation of locomotor circuits, modulation of afferent-evoked burst amplitude is observed using DA receptor agonists, but the effects on rhythm frequency are not as clear (Gordon and Whelan, 2006). Although it is not clear yet why there is a difference between DA modulation of druginduced versus afferent-evoked locomotion, one possibility is that afferent-evoked locomotor activity can be affected by modulation of afferent transmission as well as at the central pattern generator (CPG). Because DA can affect neuronal and network function through $\mathrm{D}_{1}, \mathrm{D}_{2}$, and $\mathrm{D}_{3}$ receptors (Maitra et al., 1993; Seth et al., 1993; Gajendiran et al., 1996; Barriere et al., 2004; Clemens and Hochman, 2004; Madriaga et al., 2004), more work is required before this issue can be resolved.

Our data suggest that DA is blocking the transient $\mathrm{K}^{+}$current $I_{\mathrm{A}}$ (Connor, 1978), because 4-AP partly mimicked the effects of $\mathrm{DA}$, and subsequent DA application in the presence of 4-AP was occluded (Harris-Warrick et al., 1995). Unlike apamin, however, 4-AP did not increase the $f-I$ slope. Surprisingly, dopamine could not further increase $f-I$ slope after the application of 4-AP, although $\mathrm{SK}_{\mathrm{Ca}}$ conductances are presumably still capable of being modulated. We do not yet know the reason why the effects of DA were attenuated under these conditions.

\section{Synaptic transmission}

In the striatum and nucleus accumbens of mammals, DA, acting though $\mathrm{D}_{1}$ receptors, can increase NMDA and AMPA currents (Greengard, 2001; Zhang et al., 2005) likely by causing an increase in postsynaptic $\mathrm{Ca}^{2+}$ concentrations (Yang 2000). Com- 
parable work examining DA modulation of spinal neurons in terrestrial vertebrates is limited. The only study we are aware of was performed in the chick in which $\mathrm{D}_{1}$ agonists increased kainite receptor currents by $>200 \%$ (Smith et al., 1995). The increase in the frequency of mEPSCs in our study suggests that DA increases the probability of glutamatergic release. Activation of silent synapses can also give rise to increased frequency of mEPSCs, and an increased frequency of events could be attributable to incorporation of AMPA receptors as has been observed in the nucleus accumbens (Mangiavacchi and Wolf, 2004). Although conventional thought regards increases in mEPSC amplitude as evidence of postsynaptic effects, there is evidence that synchronized multivesicular release can result in an enhanced amplitude of miniature currents (Oertner et al., 2002; Gordon and Bains, 2005). Our AMPA puff experiments suggest that at least part of the actions of DA are postsynaptic because AMPA-evoked currents are increased in the presence of bath-applied DA. Increases in glutamatergic transmission could promote recurrent excitation within the network, and the dramatic increase in sEPSC frequency is consistent with this hypothesis. Another way in which DA could increase net excitatory drive is to reduce GABA or glycine currents as has been observed in the nucleus accumbens (Nicola and Malenka, 1997; Gao et al., 2003; Hjelmstad, 2004). Interestingly in the lamprey, DA can decrease IPSPs from commissural neurons onto motoneurons but not from lateral interneurons (Kemnitz, 1997). Extracellular recordings from Renshaw cells illustrate that DA increases burst discharge in these cells after stimulation of recurrent collaterals (Seth et al., 1993). This would be expected to decrease motoneuronal excitability because Renshaw cells are inhibitory cells known to project to motoneurons. Thus, although the net effect of DA onto motoneurons is excitatory, this effect is most likely a result of a complex interaction between network, synaptic, and intrinsic properties.

An important caveat is that DA may not have similar actions in different cells in the ventral horn. Heterogeneity of actions is a hallmark of monoaminergic modulatory actions in the spinal cord (Kemnitz, 1997; Beato and Nistri, 1998; Rekling et al., 2000; Schmidt and Jordan, 2000; Gordon and Whelan, 2006), and there is reason to suspect that DA may also have different effects on different classes of ventral horn neurons depending on DA receptor distribution (Dubois et al., 1986; Maitra et al., 1993; Seth et al., 1993; Levant and McCarson, 2001). In other regions of the brain, DA increases EPSCs in layer II-III pyramidal neurons (GonzalezIslas and Hablitz, 2003) in rat prefrontal cortex but decreases EPSCs in the nucleus of the solitary tract (Kline et al., 2002). Thus, different classes of cells in the spinal cord will need to be examined to build a full picture of DA modulation. Another caveat is that we focused on AMPA conductances, and DA is also known to affect NMDA conductances in other areas of the brain and in the spinal cord of the lamprey.

\section{Dopaminergic effects on network function}

Because DA can modulate fictive locomotor pattern and frequency (Smith et al., 1988; Kiehn and Kjaerulff, 1996; Jiang et al., 1999a; Whelan et al., 2000; Barriere et al., 2004; Madriaga et al., 2004), it has been assumed that it modulates network interneurons that form part of the spinal CPG. To test these ideas at a cellular level, we examined the effects of DA on Hb9 cells. Hb9 interneurons exhibit electrophysiological signatures consistent with candidate rhythm-generating interneurons (Wilson et al., 2005). An exciting possibility is that these neurons form part of the spinal cord CPG kernel (Hinckley et al., 2005b). Our data illustrate that $\mathrm{Hb} 9$ cells are capable of oscillatory activity in either the absence or the presence of TTX, confirming previous reports (Hinckley et al., 2005; Wilson et al., 2005). Here we demonstrate that DA increases the excitability of these cells and is necessary but not sufficient to promote interneuronal rhythmicity. This adds to data from the late neonatal mouse in which DA is also essential for evoking rhythmic activity recorded from ventral root neurograms (Jiang et al., 1999a). Although we were able to replicate most aspects of $\mathrm{Hb} 9$ electrophysiology, one difference was that the voltage dependency of burst frequency was opposite to that observed in another report (Wilson et al., 2005). Without performing specific experiments to test for the effects of specific conductances (e.g., T-type), it is premature to speculate on the mechanisms underlying the oscillations we observed.

Although it is too early to say that these specific populations of interneurons are necessary and sufficient components of the spinal CPG, our intracellular data from $\mathrm{Hb} 9$ cells are consistent with dopaminergic effects on increasing the stability of spinal networks. However, Hb9 cells likely comprise a small fraction of interneurons affected by DA because our extracellular recordings demonstrate that DA depolarizes interneuronal populations that project into the VLF, and our intracellular data show that release of neurotransmitter from premotor interneurons is increased by DA. Indeed, we were able to record conditional oscillations from putative type 2 cells, which have an electrophysiological signature consistent with $\mathrm{GFP}^{+} / \mathrm{Hb} 9$-negative interneurons.

\section{References}

Barriere G, Mellen N, Cazalets JR (2004) Neuromodulation of the locomotor network by dopamine in the isolated spinal cord of newborn rat. Eur J Neurosci 19:1325-1335.

Beato M, Nistri A (1998) Serotonin-induced inhibition of locomotor rhythm of the rat isolated spinal cord is mediated by the 5 -HT1 receptor class. Proc Biol Sci 265:2073-2080.

Bjorklund A, Skagerberg G (1979) Evidence for a major spinal cord projection from the diencephalic A11 dopamine cell group in the rat using transmitter-specific fluorescent retrograde tracing. Brain Res 177:170-175.

Bond CT, Maylie J, Adelman JP (2005) SK channels in excitability, pacemaking and synaptic integration. Curr Opin Neurobiol 15:305-311.

Christie KJ, Whelan PJ (2005) Monoaminergic establishment of rostrocaudal gradients of rhythmicity in the neonatal mouse spinal cord. J Neurophysiol 94:1554-1564.

Clemens S, Hochman S (2004) Conversion of the modulatory actions of dopamine on spinal reflexes from depression to facilitation in $\mathrm{D}_{3}$ receptor knock-out mice. J Neurosci 24:11337-11345.

Clemens S, Sawchuk MA, Hochman S (2005) Reversal of the circadian expression of tyrosine-hydroxylase but not nitric oxide synthase levels in the spinal cord of dopamine D3 receptor knockout mice. Neuroscience 133:353-357.

Clemens S, Rye D, Hochman S (2006) Restless legs syndrome: revisiting the dopamine hypothesis from the spinal cord perspective. Neurology 67:125-130.

Connor JA (1978) Slow repetitive activity from fast conductance changes in neurons. Fed Proc 37:2139-2145.

Dubois A, Savasta M, Curet O, Scatton B (1986) Autoradiographic distribution of the D1 agonist $\left[{ }^{3} \mathrm{H}\right]$ SKF 38393, in the rat brain and spinal cord. Comparison with the distribution of D2 dopamine receptors. Neuroscience 19:125-137.

Fedirchuk B, Wenner P, Whelan PJ, Ho S, Tabak J, O’Donovan MJ (1999) Spontaneous network activity transiently depresses synaptic transmission in the embryonic chick spinal cord. J Neurosci 19:2102-2112.

Gajendiran M, Seth P, Ganguly DK (1996) Involvement of the presynaptic dopamine D2 receptor in the depression of spinal reflex by apomorphine. NeuroReport 7:513-516.

Gao WJ, Wang Y, Goldman-Rakic PS (2003) Dopamine modulation of 
perisomatic and peridendritic inhibition in prefrontal cortex. J Neurosci 23:1622-1630.

Gerin C, Becquet D, Privat A (1995) Direct evidence for the link between monoaminergic descending pathways and motor activity. I. A study with microdialysis probes implanted in the ventral funiculus of the spinal cord. Brain Res 704:191-201.

Gonzalez-Islas C, Hablitz JJ (2003) Dopamine enhances EPSCs in layer IIIII pyramidal neurons in rat prefrontal cortex. J Neurosci 23:867-875.

Gordon GR, Bains JS (2005) Noradrenaline triggers multivesicular release at glutamatergic synapses in the hypothalamus. J Neurosci 25:11385-11395.

Gordon IT, Whelan PJ (2006) Monoaminergic control of cauda-equinaevoked locomotion in the neonatal mouse spinal cord. J Neurophysiol 96:3122-3129.

Greengard P (2001) The neurobiology of slow synaptic transmission. Science 294:1024-1030.

Harris-Warrick RM, Coniglio LM, Barazangi N, Guckenheimer J, Gueron S (1995) Dopamine modulation of transient potassium current evokes phase shifts in a central pattern generator network. J Neurosci 15:342-358.

Hinckley CA, Ziskind-Conhaim L (2006) Electrical coupling between locomotor-related excitatory interneurons in the mammalian spinal cord. J Neurosci 26:8477-8483.

Hinckley C, Seebach B, Ziskind-Conhaim L (2005a) Distinct roles of glycinergic and GABAergic inhibition in coordinating locomotor-like rhythms in the neonatal mouse spinal cord. Neuroscience 131:745-758.

Hinckley CA, Hartley R, Wu L, Todd A, Ziskind-Conhaim L (2005b) Locomotor-like rhythms in a genetically distinct cluster of interneurons in the mammalian spinal cord. J Neurophysiol 93:1439-1449.

Hjelmstad GO (2004) Dopamine excites nucleus accumbens neurons through the differential modulation of glutamate and GABA release. J Neurosci 24:8621-8628.

Hochman S, Garraway SM, Machacek DW, Shay BL (2001) Motor neurobiology of the spinal cord, pp 47-87. Boca Raton, FL: CRC.

Holstege JC, Van Dijken H, Buijs RM, Goedknegt H, Gosens T, Bongers CM (1996) Distribution of dopamine immunoreactivity in the rat, cat and monkey spinal cord. J Comp Neurol 376:631-652.

Hounsgaard J, Hultborn H, Jespersen B, Kiehn O (1988) Bistability of alpha-motoneurones in the decerebrate cat and in the acute spinal cat after intravenous 5-hydroxytryptophan. J Physiol (Lond) 405:345-367.

Hultborn H, Brownstone RB, Toth TI, Gossard JP (2004) Key mechanisms for setting the input-output gain across the motoneuron pool. Prog Brain Res 143:77-95.

Jankowska E (2001) Spinal interneuronal systems: identification, multifunctional character and reconfigurations in mammals. J Physiol (Lond) 533:31-40.

Jiang Z, Carlin KP, Brownstone RM (1999a) An in vitro functionally mature mouse spinal cord preparation for the study of spinal motor networks. Brain Res 816:493-499.

Jiang Z, Rempel J, Li J, Sawchuk MA, Carlin KP, Brownstone RM (1999b) Development of L-type calcium channels and a nifedipine-sensitive motor activity in the postnatal mouse spinal cord. Eur J Neurosci 11:3481-3487.

Jordan LM, Schmidt BJ (2002) Propriospinal neurons involved in the control of locomotion: potential targets for repair strategies? Prog Brain Res 137:125-139.

Kemnitz CP (1997) Dopaminergic modulation of spinal neurons and synaptic potentials in the lamprey spinal cord. J Neurophysiol 77:289-298.

Kemnitz CP, Strauss TR, Hosford DM, Buchanan JT (1995) Modulation of swimming in the lamprey, Petromyzon marinus, by serotonergic and dopaminergic drugs. Neurosci Lett 201:115-118.

Kernell D (2006) The motoneurone and its muscle fibres. New York: Oxford UP.

Kiehn O, Kjaerulff O (1996) Spatiotemporal characteristics of 5-HT and dopamine-induced rhythmic hindlimb activity in the in vitro neonatal rat. J Neurophysiol 75:1472-1482.

Kline DD, Takacs KN, Ficker E, Kunze DL (2002) Dopamine modulates synaptic transmission in the nucleus of the solitary tract. J Neurophysiol 88:2736-2744.
Levant B, McCarson KE (2001) D(3) dopamine receptors in rat spinal cord: implications for sensory and motor function. Neurosci Lett 303:9-12.

Madriaga MA, McPhee LC, Chersa T, Christie KJ, Whelan PJ (2004) Modulation of locomotor activity by multiple 5-HT and dopaminergic receptor subtypes in the neonatal mouse spinal cord. J Neurophysiol 92:1566-1576.

Maitra KK, Seth P, Thewissen M, Ross HG, Ganguly DK (1993) Dopaminergic influence on the excitability of antidromically activated Renshaw cells in the lumbar spinal cord of the rat. Acta Physiol Scand 148:101-107.

Mangiavacchi S, Wolf ME (2004) D1 dopamine receptor stimulation increases the rate of AMPA receptor insertion onto the surface of cultured nucleus accumbens neurons through a pathway dependent on protein kinase A. J Neurochem 88:1261-1271.

Martin-Caraballo M, Greer JJ (2000) Development of potassium conductances in perinatal rat phrenic motoneurons. J Neurophysiol 83:3497-3508.

McPherson DR, Kemnitz CP (1994) Modulation of lamprey fictive swimming and motoneuron physiology by dopamine, and its immunocytochemical localization in the spinal cord. Neurosci Lett 166:23-26.

Miles GB, Dai Y, Brownstone RM (2005) Mechanisms underlying the early phase of spike frequency adaptation in mouse spinal motoneurones. J Physiol (Lond) 566:519-532.

Nicola SM, Malenka RC (1997) Dopamine depresses excitatory and inhibitory synaptic transmission by distinct mechanisms in the nucleus accumbens. J Neurosci 17:5697-5710.

Nisenbaum ES, Xu ZC, Wilson CJ (1994) Contribution of a slowly inactivating potassium current to the transition to firing of neostriatal spiny projection neurons. J Neurophysiol 71:1174-1189.

O'Donovan MJ (1987) Developmental approaches to the analysis of vertebrate central pattern generators. J Neurosci Methods 21: 275-286.

Oertner TG, Sabatini BL, Nimchinsky EA, Svoboda K (2002) Facilitation at single synapses probed with optical quantal analysis. Nat Neurosci 5:657-664.

Pierre J, Mahouche M, Suderevskaya EI, Reperant J, Ward R (1997) Immunocytochemical localization of dopamine and its synthetic enzymes in the central nervous system of the lamprey Lampetra fluviatilis. J Comp Neurol 380:119-135.

Qu S, Ondo WG, Zhang X, Xie WJ, Pan TH, Le WD (2006) Projections of diencephalic dopamine neurons into the spinal cord in mice. Exp Brain Res 168:152-156.

Rekling JC, Funk GD, Bayliss DA, Dong XW, Feldman JL (2000) Synaptic control of motoneuronal excitability. Physiol Rev 80:767-852.

Schmidt BJ, Jordan LM (2000) The role of serotonin in reflex modulation and locomotor rhythm production in the mammalian spinal cord. Brain Res Bull 53:689-710.

Schoppa NE, Westbrook GL (1999) Regulation of synaptic timing in the olfactory bulb by an A-type potassium current. Nat Neurosci 2:1106-1113.

Schotland J, Shupliakov O, Wikstrom M, Brodin L, Srinivasan M, You ZB, Herrera-Marschitz M, Zhang W, Hokfelt T, Grillner S (1995) Control of lamprey locomotor neurons by colocalized monoamine transmitters. Nature 374:266-268.

Seth P, Gajendiran M, Maitra KK, Ross HG, Ganguly DK (1993) Evidence for D1 dopamine receptor-mediated modulation of the synaptic transmission from motor axon collaterals to Renshaw cells in the rat spinal cord. Neurosci Lett 158:217-220.

Sharifullina E, Ostroumov K, Nistri A (2004) Activation of group I metabotropic glutamate receptors enhances efficacy of glutamatergic inputs to neonatal rat hypoglossal motoneurons in vitro. Eur J Neurosci 20:1245-1254.

Skoog B, Noga BR (1995) Dopaminergic control of transmission from group II muscle afferents to spinal neurones in the cat and guinea-pig. Exp Brain Res 105:39-47.

Smith JC, Feldman JL, Schmidt BJ (1988) Neural mechanisms generating locomotion studied in mammalian brain stem-spinal cord in vitro. FASEB J 2:2283-2288.

Smith DO, Lowe D, Temkin R, Jensen P, Hatt H (1995) Dopamine enhances glutamate-activated currents in spinal motoneurons. J Neurosci 15:3905-3912.

Svensson E, Woolley J, Wikstrom M, Grillner S (2003) Endogenous dopa- 
minergic modulation of the lamprey spinal locomotor network. Brain Res 970:1-8.

Viana F, Bayliss DA, Berger AJ (1993) Multiple potassium conductances and their role in action potential repolarization and repetitive firing behavior of neonatal rat hypoglossal motoneurons. J Neurophysiol 69:2150-2163.

Wallen P, Buchanan JT, Grillner S, Hill RH, Christenson J, Hokfelt T (1989) Effects of 5-hydroxytryptamine on the afterhyperpolarization, spike frequency regulation, and oscillatory membrane properties in lamprey spinal cord neurons. J Neurophysiol 61:759-768.

Weil-Fugazza J, Godefroy F (1993) Dorsal and ventral dopaminergic innervation of the spinal cord: functional implications. Brain Res Bull 30:319-324.

Whelan P, Bonnot A, O'Donovan MJ (2000) Properties of rhythmic activity generated by the isolated spinal cord of the neonatal mouse. J Neurophysiol 84:2821-2833.

Wikstrom MA, Grillner S, El Manira A (1999) Inhibition of N- and L-type
$\mathrm{Ca}^{2+}$ currents by dopamine in lamprey spinal motoneurons. NeuroReport 10:3179-3183.

Wilson JM, Hartley R, Maxwell DJ, Todd AJ, Lieberam I, Kaltschmidt JA, Yoshida Y, Jessell TM, Brownstone RM (2005) Conditional rhythmicity of ventral spinal interneurons defined by expression of the $\mathrm{Hb} 9$ homeodomain protein. J Neurosci 25:5710-5719.

Yang SN (2000) Sustained enhancement of AMPA receptor- and NMDA receptor-mediated currents induced by dopamine D1/D5 receptor activation in the hippocampus: an essential role of postsynaptic $\mathrm{Ca}^{2+}$. Hippocampus 10:57-63.

Yoshida M, Tanaka M (1988) Existence of new dopaminergic terminal plexus in the rat spinal cord: assessment by immunohistochemistry using anti-dopamine serum. Neurosci Lett 94:5-9.

Zhang TA, Hendricson AW, Morrisett RA (2005) Dual synaptic sites of $\mathrm{D}$ (1)-dopaminergic regulation of ethanol sensitivity of NMDA receptors in nucleus accumbens. Synapse 58:30-44. 